\title{
SYNERGY BETWEEN LiDAR, RADARSAT-2 AND SPOT-5 IMAGES FOR THE DETECTION AND MAPPING OF WETLAND VEGETATION IN THE DANUBE DELTA
}

\author{
Simona Niculescu, Cédric Lardeux, Ion Grigoras, Jenica Hanganu, Laurence David
}

\begin{abstract}
Wetlands are among the most productive natural environments on Earth, as they harbor exceptional biological diversity. For this paper, our study site was the Danube Delta. The biodiversity of the Danube Delta is extraordinary and it possesses one of the largest reed beds in the world. The main goal of our paper was to recognize, characterize and map the main vegetation units of the Danube Delta. The paper emphasizes the importance of the joint use of LiDAR measurements (acquired in May 2011), RADARSAT-2 radar data (acquired on 4 June 2011) and SPOT-5 optical data (acquired on 25 May 2011). LiDAR data allow for the characterization of vegetation height within centimeter accuracy $(10 \mathrm{~cm})$. The radar measurements are based on $\mathrm{C}$-band, providing additional information about the structure of the vegetation cover. The simultaneous acquisition of $\mathrm{HH}, \mathrm{HV}, \mathrm{VV}$ and $\mathrm{VH}$ polarizations enabled us to discriminate between the targets, depending on their responses to the various polarizations, by calculating their polarimetric signatures. By linking multispectral LiDAR and radar data, information can be obtained about vegetation reflectance and height as well as the backscattering mechanism, allowing for improved mapping and characterization accuracy $(90.60 \%$ mean accuracy). An accuracy assessment of the classification results was evaluated against the vegetation data recorded in the field.
\end{abstract}

Index Terms - Wetlands, Danube Delta, detection and mapping vegetation, multisensor data integration-LiDAR, RADARSAT-2 and SPOT-5.

\section{INTRODUCTION}

\section{A. Wetlands and remote sensing. Objectives}

WETLANDS are transitional environments between earth and water; they represent a valuable asset because of their richness and the ecosystem services they render. This ecotone position gives them a particular functioning creating particular conditions, highly favorable to biodiversity. Presenting a wide diversity of vegetation and animal species, these areas are characterized by their high evolution potential (vegetation successions are relatively rapid). Wetland hydric conditions, which vary in time and space, have generated specific plant

The work was supported in part by the Laboratoire LETG-Brest, Géomer, UMR 6554 CNRS and by the Université de Bretagne Occidentale (Projets Exploratoires).

Simona Niculescu: Laboratoire LETG-Brest, Géomer, UMR 6554 CNRS, IUEM - UBO, rue Dumont d'Urville, F-29280 Plouzané, France, simona.niculescu@univ-brest.fr

Cédric Lardeux: Office National des Forêts 2, avenue de Saint-Mandé, F-75570 Paris Cedex 12, France, clardeux@gmail.com

Ion Grigoras: Danube Delta National Institute for Research and Development. Str. Babadag, n¹65, 820112, Tulcea, Romania, ion.grigoras@ ddni.ro adaptations (resistance to hydric stress, resistance to halin stress) and important diversification in these environments. Threatened by human activities and global changes, this natural heritage is of particular interest. Wetland management and conservation present important environmental, economic and social challenges. In this context, this article proposes a remote sensing methodology developed for the mapping of habitats in the Danube delta.

Today, satellites are an essential component of vegetation management in humid areas and, more generally, of environmental management. Because satellite remote sensing provides a large spatial view combined with a relatively high return frequency, it is a very cost-effective tool for wetland monitoring [1]. Satellite remote sensing increasingly presents advantages for inventorying and monitoring all types of wetlands [2]. Optical data provide useful information for inventorying wetland vegetation. The very high spatial resolution of optical satellite imagery, such as SPOT-6, SPOT$7(1,5 \mathrm{~m})$ and high resolution optical sensors, such as IKONOS and Quickbird (between 2.5-4.0 m), makes them ideal for capturing small features of wetlands. Another advantage is the existence of a NIR band (strong reflectance for vegetation and strong absorption for water of wetlands). The limitation of optical imagery is that its wavelengths are short enough (0.4$3.0 \mu \mathrm{m})$ to be scattered by clouds. Because atmospheric scattering decreases with increasing wavelength, longer Synthetic aperture radar (SAR) wavelengths are able to penetrate clouds and are not limited to acquiring under cloudfree conditions. This is the case for C-band SAR $(5.3 \mathrm{~cm}$ microwaves), such as the Canadian Radio Detection And Ranging Satellite (RADARSAT-2) used in this study. SAR sensors also have the potential to penetrate vegetation cover and detect sub-canopy conditions, which can be very beneficial for wetland monitoring [1]. Light Detection and Ranging (LiDAR) is an emerging and excellent tool for probing the geometry of vegetation and terrain. In the case of the analysis in the field of optical and radar data, the vertical component is not directly measured and, as a result, must be modeled [3]. LiDAR remote

Jenica Hanganu: Danube Delta National Institute for Research and Development. Str. Babadag, n 165, 820112, Tulcea, Romania, jenicahanganu@ddni.ro

Laurence David: Laboratoire LETG-Brest, Géomer, UMR 6554 CNRS, IUEM - UBO, rue Dumont d'Urville, F-29280 Plouzané, France, laurence.david@univ-brest.fr 
sensing provides a simple direct measurement of vegetation vertical structure permitting the recovery of height and vertical diversity [3].

In this article, we focus on LiDAR data, different satellite data (optical and radar) and terrain data that can be used to improve wetland detection and vegetation classification. We propose a method based on multisensor imagery analysis to characterize vegetation patterns in the Danube delta.

The objective of this research was to illustrate how multisensor and multi-platform remote sensing techniques can be used in the detection and mapping of vegetation in the Danube Delta. The primary objective was to compare the capability of individual remote sensing (LiDAR, RADARSAT-2, Satellite Pour l'Observation de la Terre -SPOT-5) data sets to recognize the vegetation classes in the delta. We evaluated the accuracy of the wetland maps derived from RADARSAT-2 and SPOT-5 data, combined with high-resolution LiDAR elevation data. We statistically combined structural information from LiDAR, radar and passive optical sensors in an attempt to improve the accuracy of our estimated classes of vegetation in a complex, wetland-rich vegetation mosaic.

Such a multi-source (optical, radar and LiDAR data) approach focusing on vegetation has not been carried out in the Danube Delta to date.

\section{B. Vegetation mapping and wetland detection}

The large number of plant species and the way they are interwoven into the delta landscape creates strong spatial variability, complicating wetland mapping using images. Wetland species appear to vary greatly in their chlorophyll and biomass reflectance as a function of plant species and hydrologic regime [4].

Wetlands have proven difficult to map using satellite remote sensing [5], [6] because their spectral and spatial characteristics are highly context-dependent [7]. Accurate wetland mapping is an important tool for understanding wetland functions and monitoring their response to natural and anthropogenic actions [8].

Many researchers have used multispectral data, such as Landsat Thematic Mapper (TM) and SPOT imagery, to identify general vegetation classes or to attempt to discriminate broad vegetation communities [9], [10], [11]; researchers have also used hyperspectral data to discriminate and map wetland vegetation at the species level [12], [13], [14], [15], [16] and very high resolution sensors [17], [18], [19], [20]. Multispectral and hyperspectral remote sensing have been used to map structural metrics at a moderate resolution and on broad scales. Davranche et al., (2010) [21] demonstrated how classification trees applied to time series of SPOT-5 images are a powerful and reliable tool for monitoring wetland vegetation under different hydrological regimes.

The presence of water, lakes, rivers, deltas or vegetation is very well depicted by means of active microwaves using the backscattering mechanism, with very low responses for single backscatter and strong responses for double-bounce (for instance, for flooded vegetation) [22], [23], [24], [25]. Multipolarization and multi-frequency radars are also used for the classification of wetland vegetation depending on their wavelengths, polarizations and backscattering mechanism, which are associated with the density and size of the vegetation [26], [23], [27]. Based on RADARSAT-2 data (polarimetric sensors with a spatial resolution of less than $10 \mathrm{~m}$ ), characterizations of herbaceous and tree vegetation (peat lands, broad-leaved trees, conifers) were carried out [28], [29], [30], [31]. Research has also shown that C-band RADARSAT SAR is able to detect stading water beneath fully foliated shrubs [32] and forest cover [33]. Grings et al., 2006 [34] analyzed multitemporal/multi-polarized radar backscatter from the same two types of marshes (junco and cortadera) during tidal events using only ENVISAT Advanced Synthetic Aperture Radar (ASAR) (C-band, $\mathrm{HH}$ and VV polarization).

Most research suggests that L-band data are necessary for forest and C-band for herbaceous wetland detection [35], [36]. The preference for L-HH imagery for investigations of forested wetlands was reiterated [37]. The sensitivity of microwave energy to water and its ability to penetrate vegetative canopies make SAR ideal for the detection of the hydrologic features under vegetation [38], [39], [40], [41], [42], [43].

$\mathrm{X}$-band SAR satellite, such as TerraSAR-X, launched in 2007, are equipped with sensors with a resolution close to one meter, offering interesting opportunities for observation of wetland [44], [45], [46] [47]. Schuster et al., 2015 [48] showed that TerraSAR-X time-series are relevant for mapping herbaceous wetland vegetation. Betbeder et al., 2014 [49] evaluated several parameters (backscattering coefficients and polarimetric parameters) derived from six dual-pol TerraSAR$\mathrm{X}$ images to precisely map the distribution of vegetation formations in wetland areas. They showed the potential of TerraSAR-X (X-band) and, more specifically, of a polarimetric parameter for grassland vegetation mapping in wetlands.

Airborne laser instruments, such as LiDAR, represent innovative tools for the detection and the mapping of wetlands [50], [51], [52], [53]. After the successful application of LiDAR to forestry and the availability of LiDAR technology, new research has been carried out in other ecosystems.

Several studies have used topographic LiDAR data to map coastal habitats and, as part of the investigation, evaluated their vertical accuracy to determine the appropriateness of the data for use in the intended application. Populus et al. (2001) [54] asked the fundamental question of where the LiDAR pulse is reflected on the vegetation. They determined that, in dense vegetation stands, the approximate height of the LiDAR return correlates to one-half of the vegetation height. Gopfert and Heipke (2006) [55] documented a positive bias that varied as a function of vegetation parameters such as height, density and species type [51].

LiDAR techniques are used to measure vegetation height in relation to the soil surface in wetlands [56], [57], [58], [59]. Hopkinson et al. $(2004,2005)$ [60], [57] provide an assessment of lidar-based errors in ground elevation and vegetation height and a sensitivity analysis of hydrological friction parameter estimates for six dominant vegetation classes within a boreal wetland environment. LiDAR ground height estimation was most problematic for aquatic vegetation owing to weak laser 
backscatter from the saturated ground conditions typically associated with this vegetation class. Large errors in the height measurement can be registered of vegetation emerging above a water body because the water level is not detected properly and the water depth is unknown. The openness and orientation of vegetation foliage (i.e., minimal projection of horizontal area) would appear to facilitate the penetration of the laser pulse in the surface of vegetation classes. The inability to penetrate dense vegetation is one example of a systematic error.

LiDAR data also allow for the study of volume structure in habitats necessary for ecosystem functioning [61], [62]. They also allow for characterization and analysis of the ecosystem structure in coastal humid areas [63], [64], [51], [43]. In vegetation studies, it is useful to select a near-infrared wavelength to maximize the return signal and minimize background noise [3].

However, an analysis of the LiDAR data alone does not allow for discrimination of the height different vegetal communities within a same stratum, hence the interest in combining LiDAR data with other satellite data types, such as radar data [1] and/or data with high spatial resolution optics [1], [65], [66], [67], [68]. Slatton et al. (2001) [69] combined LiDAR data with interferometric radar data to improve estimates of vegetation heights. Hyde et al. (2006) [70] show how LiDAR is the best single sensor for estimating canopy height and biomass. The addition of ETM+ metrics significantly improved LiDAR estimates of large tree structures, whereas Quickbird and InSAR/SAR improved estimates marginally or not at all. A combination of all sensors was more accurate than LiDAR alone, but only marginally better than a combination of LiDAR and ETM+.

\section{Study area. Habitat description of the Danube Delta and the Caraorman region}

The test site is located in the Caraorman region of the Danube Delta Biosphere Reserve. The total area of the "Danube Delta" Biosphere Reserve is approximately $5800 \mathrm{~km}^{2}$ in Romania and more than $50 \mathrm{~km}^{2}$ in Ukraine [71]. The Danube Delta itself refers to the area between the three main branches of the Danube River (from North to South: the Chilia, Sulina, and Sfântu Gheorghe (St. George) branches), which are located in Romania with a total area of $3510 \mathrm{~km}^{2}$; this is the third largest delta in Europe after the Volga Delta $\left(13000 \mathrm{~km}^{2}\right)$ and the Kuban Delta (4 $300 \mathrm{~km}^{2}$ ) (Fig. 1).

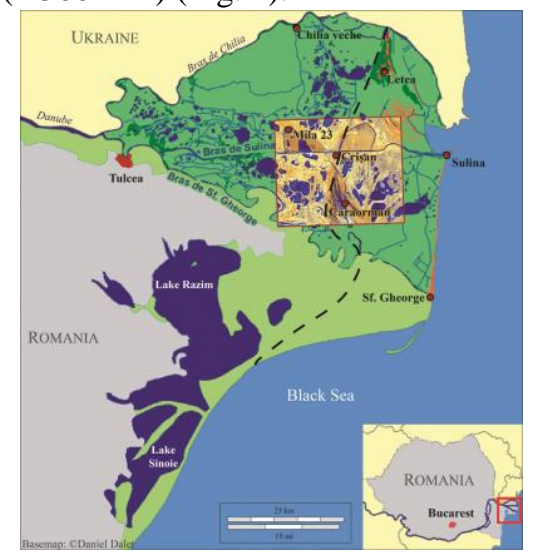

Fig. 1. The Danube Delta and geographical location of the study sample.

The Danube Delta, Romania's youngest landmass, is a fluvial-maritime floodplain covering two floristic provinces, the lower Danube (ponto-sarmatic) and the Black Sea (euxinic) [72]. The diversified geomorphology, soils and hydrological conditions favor the proliferation of a large number of aquatic, semi-desert and saline habitats.

A vegetation map of the delta produced by Hanganu et al., 2002 [71] shows 44 types of vegetation grouped into eight categories in the Romanian delta and a significant part of the Ukraine delta. These units consist of the following: flood plain forests; beach/sea vegetation and dune vegetation; salt-tolerant vegetation; sandy steppe meadows; river elevation meadows; dune forests; marsh vegetation and aquatic vegetation. The dominant species is Phragmites australis, which is usually accompanied by hydrophilous species such as Typha angustifolia, Schoenoplectus lacustris, Sparganium erectum, and Thelypteris palustris.

In this paper, using different satellite images, we study the different units for dune vegetation, salt-tolerant vegetation, marsh vegetation, dune forests and floodplain forest areas.

The study area was the Caraorman region, located, from a vegetation perspective, between the river area and the transitory area of the delta, in the ancient barrier beaches region. The dunes reach a maximum elevation of $7 \mathrm{~m}$ above sea level. The dunes are covered with open steppe vegetation such as Carex colchica, sea grape (Ephedra distachya), wild rye (Secale silvestre), Volga wild rye (Elymus giganteus) and Festuca beckeri. The depressions are forested by oak (Quercus pedunculiflora) and pubescent ash (Fraxinus pallisae). The Caraorman complex includes less elevated areas along its borders, with saline groundwater close to the soil surface. This is evident from its salt-tolerant vegetation (Puccinellia convoluta, sea lavender (Limonium gmelinii), sea rush (Juncus maritimus) and Aeluropus littoralis). These plants grow in mosaics mixed with less salt-tolerant flora and Tamarix ramosissima, Elaeagnus angustifolia and Hippophae rhamnoides bushes.

Further along the marginal areas of the delta, flooding becomes increasingly important. This is reflected by a gradual change from salt-tolerant vegetation to brackish pasture with annual cyperaceous and further to reed mace marsh, which is finally replaced by reed marsh with sedges on peat soils.

Soft wood forests are found along the river levees. Floodplain forests are dominated by white willow (Salix alba) and crack willow (S. fragilis), with indigo bush (Amorpha fruticosa) along the fringes. Alder trees (Alnus glutinosa) mixed with Salix alba are found along the narrow clayey river levees.

\section{DATASET}

The data used for this research include RADARSAT-2, LiDAR and SPOT-5 satellite data as well as ground-based spectral measurements (table 1).

TABLE 1 
SUMMARY TABLE: DATA IMPLEMENTED

\begin{tabular}{|c|c|c|}
\hline Dataset & Image date & Technical characteristics \\
\hline RADARSAT-2 & 4 June 2011 & $\begin{array}{l}\text { Mode: Standard Quad-Pol, HH, VV, HV, } \\
\text { VH } \\
\text { C-Band: } 5.6 \mathrm{~cm} \\
\text { Resolution: radar geometry: } 5.12 \mathrm{~m} \text { (line) } \\
\text { and } 4.7 \mathrm{~m} \text { (range); thrown to the ground: } \\
5.12 \mathrm{~m} \text { (line) and } 7.2 \text { (range) }\end{array}$ \\
\hline LiDAR & May 2011 & $\begin{array}{l}\text { Number of points by square meter: } 25 \\
\text { Observation of the vegetation with a } \\
\text { density fixed at } 4-5 \mathrm{~cm} \text { for } \mathrm{X}, \mathrm{Y} \text { and } 5-6 \\
\mathrm{~cm} \text { for } \mathrm{Z} \\
\text { In the near infrared band ( } 532 \mathrm{~nm}-905 \\
\mathrm{~nm} \text { ) } \\
\text { RMS: RMS X: > } 5 \mathrm{~cm} \text {; RMS Y:> } 5 \mathrm{~cm} \text {; } \\
\text { RMS Z:> } 10 \mathrm{~cm}\end{array}$ \\
\hline SPOT-5 & 25 May 2011 & $\begin{array}{c}\text { Multispectral image } \\
\text { HRG instrument (high resolution) } \\
\text { Spatial resolution: } 10 \mathrm{~m} \text { x } 10 \mathrm{~m}\end{array}$ \\
\hline $\begin{array}{l}\text { Spectroradiometric } \\
\text { measurements }\end{array}$ & May 2011 & $\begin{array}{c}\text { FieldSpec }{ }^{\circledR} \text { HandHeld spectroradiometer } \\
\text { Electromagnetic spectrum comprised } \\
\text { between } 325 \text { and } 1075 \mathrm{~nm}\end{array}$ \\
\hline
\end{tabular}

RADARSAT-2 is equipped with a SAR sensor presenting the technical advantage to be able to acquire with full polarimetry. The capacity of transmitting radar waves horizontally $(\mathrm{H})$ and vertically (V) allows for the generation of $\mathrm{HH}$ co-polarized products (such as RADARSAT-1) or VV, in cross-polarization (HV or $\mathrm{VH}$ ), in double polarization or in quadruple polarization, which improves the information content of the target. The RADARSAT-2 sensor operates in a $5 \mathrm{GHz}$ frequency band and in the $5.3 \mathrm{~cm}$ wavelength. Moreover, multipolarized data can be used to generate polarimetric signatures of the targets, which allows the interpretation of different backscatter mechanisms in different polarizations.

In this research, we used quadruple polarization data (intensity and phase difference of the $\mathrm{HH}, \mathrm{HV}, \mathrm{VV}$ polarizations) acquired on June 4, 2011. This data enabled the discrimination of different scattering mechanisms, which provided relatively detailed information about the vegetal cover.

The LiDAR data included a Digital Terrain Model (DTM) representing the terrain without surface objects (constructions, vegetation...) and a Digital Surface Model (DSM) including surface objects. The LiDAR data was acquired by the Institute of Research and Development of the Danube Delta (INCDDD), in Tulcea (Romania). First, a DEM was created from raw point data. The LiDAR data were obtained as $\mathrm{X}, \mathrm{Y}, \mathrm{Z}$ and return intensity measures were in ASCII format; therefore, the initial creation of the DEM required the identification of ground points, interpolating a continuous surface and estimating DEM cell center elevations. The topography was derived from point altimetric mappings subsequently interpolated. The accuracy was lower than $1 / 25000$ (map scale). In addition to the topographic measures carried out in the field, the topographic map has been used to check the accuracy of the orthorectification of LiDAR data. The results have shown that the difference between the LiDAR points and the points of the map XY was $<25 \mathrm{~m}$ and for $\mathrm{Z}$ was $<10 \mathrm{~cm}$.
The LiDAR mission was carried out by SC Primul Meridian SRL Slatina, in May 2011, with a RIEGL Q560 i, $240 \mathrm{kHz}$ sensor (Airborne Laser Scanning). The flight altitude was 800 $\mathrm{m}$ and the number of points by square meter was 25 . The acquisition parameters and the flight date were determined by the Danube Delta National Institute for Research and Development (DDNIRD), with the goal of obtaining good topographic accuracy and the observation of vegetation with a density fixed at 4-5 $\mathrm{cm}$ for $\mathrm{X}, \mathrm{Y}$ and 5-6 $\mathrm{cm}$ for Z. LiDAR data acquisition was carried out in the near infrared band $(532 \mathrm{~nm}$ $905 \mathrm{~nm})$ with a $60^{\circ}$ angle $\left( \pm 30^{\circ}\right)$, a pulse frequency of $110 \mathrm{KHz}$, the equivalent of 110000 pulses per second and a scanning speed of 64.8 lines/sec. The data were acquired in the UTM WGS84 geodesic system restored into Stereo70 and projected in the Dealul Piscului system using DDNIRD software (Romania). The Root Mean Square Error (RMSE) was: RMS $\mathrm{X}$ : > $5 \mathrm{~cm}$; RMS Y: $>5 \mathrm{~cm}$; and RMS Z: $>10 \mathrm{~cm}$.

A SPOT-5 multispectral image from May 23, 2011, HRG instrument (high resolution) at a spatial resolution of $10 \mathrm{~m} \mathrm{x} 10$ $\mathrm{m}$ and an incidence angle of 29.02 was also used. SPOT-5 has a 10-m spatial resolution and four bands: B1 (green: 0.50 to $0.55 \mu \mathrm{m}$ ), B2 (red: 0.61 to $0.68 \mu \mathrm{m}$ ), B3 (near-infrared NIR: 0.78 to $0.89 \mu \mathrm{m})$. SPOT scenes came with radiometric correction for distortions due to differences in sensitivity of the elementary detectors of the viewing instrument, which is the preprocessing level called 1A [73].

Lastly, ground data were also used, i.e., spectral measures of the main vegetation classes of the Danube Delta in the Caraorman region. The acquisition of spectroradiometric measurements in the field was carried out using a FieldSpec $®$ HandHeld spectroradiometer operating over a portion of the electromagnetic spectrum between $325 \mathrm{~nm}-1075 \mathrm{~nm}$. The values measured on the target fields were assessed using the reference spectrum determined during the calibration performed before the measurements and the spectral curves are displayed on the computer screen during each acquisition and the digital recording is performed directly as reflectance.

The dates were selected based on vegetation phenology and seasonal water management of the targeted habitats. The time lapse between the data acquisition dates (May 25 for SPOT-5, June 4 for RADARSAT-2 and May for LiDAR) did not lead to considerable differences because the vegetation phenology had not changed significantly between the different dates.

\section{Methodology}

From a methodological point of view, this paper covers several aspects: radar image analysis and processing, LiDAR data analysis and processing and field data processing analysis (spectral measures of the main vegetation classes in the Caraorman region, in the Danube Delta) in connection with the optical data (SPOT-5 sensor calibration), SPOT data analysis and processing; finally, multisensor data integration was proposed (Fig. 2). This data integration consists in creating layer stacks of the different sensors in order to use all available bands of each data for the classification process. Thus, we proposed the combination between SPOT-5/RADARSAT-2, 
SPOT-5/LiDAR,

RADARSAT-2/LiDAR

and SPOT5/RADARSAT-2/LiDAR.

The accuracy assessment of the classification results was evaluated against vegetation data recorded in the field.

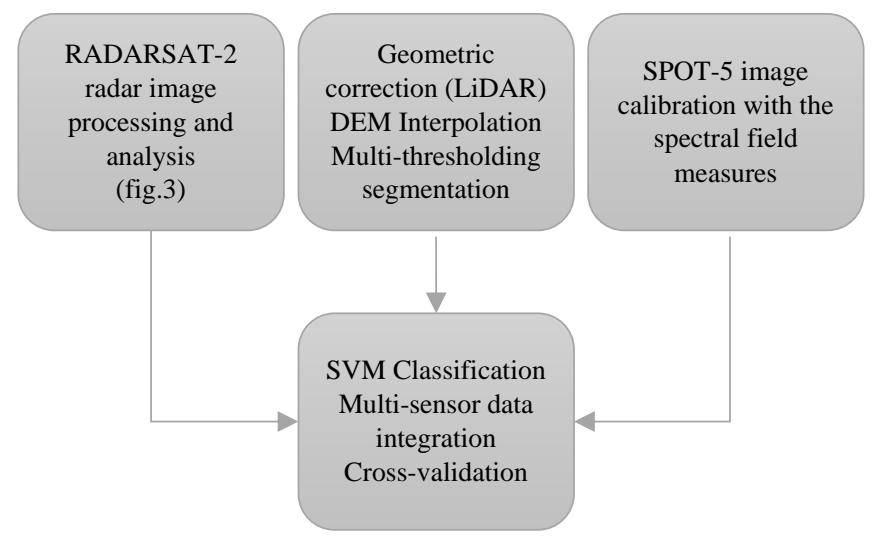

Fig. 2. Data processing procedure

\section{A. Radar methodology}

Given a fully polarimetric radar sensor such as RADARSAT2, which has the capacity to emit and receive in horizontal $(\mathrm{H})$ and vertical $(\mathrm{V})$ polarizations can thus acquire polarimetric information as described in the $\mathrm{S}$ scattering matrix:

$$
S=\left(\begin{array}{ll}
S_{h h} & S_{h v} \\
S_{v h} & S_{v v}
\end{array}\right)
$$

Because of the monostatic nature of the RADARSAT-2 data, and based on reciprocity theorem we can assume that the terms $\mathrm{S}_{\mathrm{hv}}$ and $\mathrm{S}_{\mathrm{vh}}$ can be considered equal. Based on the backscattering matrix, we deduce the $\mathrm{T}$ coherence matrix as:

$$
\begin{gathered}
k_{p}=\frac{1}{\sqrt{2}}\left(\begin{array}{ccc}
S_{h h} & + & S_{v v} \\
S_{h h} & - & S_{v v} \\
2 S_{h v}
\end{array}\right) \\
\mathrm{T}=\left\langle k_{p} k_{p}^{* T}\right\rangle
\end{gathered}
$$

Where $k_{p} k_{p}$ represents the target representative vector of the Pauli basis. <> refers to the averaging carried out during the multi-looking mode (or filtering) necessary for the use of the incoherent indices.

Therefore, this representation is based on a physical representation of the backscattering mechanisms of the observed target, odd bounce (as on a bare soil). Equation (4) represents the single-bounce scattering (e.g. dominant on bare soil or water), equation (5) the double-bounce (e.g. soil-tree trunk or soil-built-up area), and equation (6) volume scattering (e.g. dominant in forests).

$$
\begin{aligned}
& 1 / \sqrt{2}\left|S_{h h}+S_{v v}\right|^{2} \\
& 1 / \sqrt{2}\left|S_{h h}-S_{v v}\right|^{2}
\end{aligned}
$$

$$
1 / \sqrt{2}\left|S_{h v}\right|^{2}
$$

In addition, we extract a local heterogeneity indicator based on coefficients of variation $C_{v}$ of the extracted intensities where $\sigma$ and $\mu$ represent the standard deviation and mean estimated over $5 \times 5$ neighborhood.

$$
C_{v}=\left(\frac{\sigma}{\mu}\right)
$$

The three parameters $\mathrm{H} / \mathrm{A} / \alpha$ represent the entropy, anisotropy and the alpha angle. The entropy parameter characterizes the polarimetric disorder level among the three scattering mechanisms in terms of scattering degree of randomness, the anisotropy characterizes the relative importance of secondary scattering mechanisms, and the $\alpha$ parameter provides information about the type of scattering mechanism (simple, double bounce or volume scattering).

The RADARSAT-2 SAR images were pre-processed to standardize the satellite recorded image brightness, rectify the image geometry and filter image noise. Although cubic convolution is considered an adequate resampling method for preserving structures and linear features in radar images, we applied the nearest neighbor method to maintain, as much as possible, the original radiometry before filtering. The speckle inherent in radar images necessitates the use of filtering processes prior to other processing. The SAR image was filtered by means of the adaptive filter (Lee filter). This filter is based on the minimization of mean square error between the estimation of radiometric value of the pixel and the real value. We used PolSARpro software for the extraction of the polarimetric indices (intensity and entropy) and Map Ready for the orthorectification (figure 3 ).

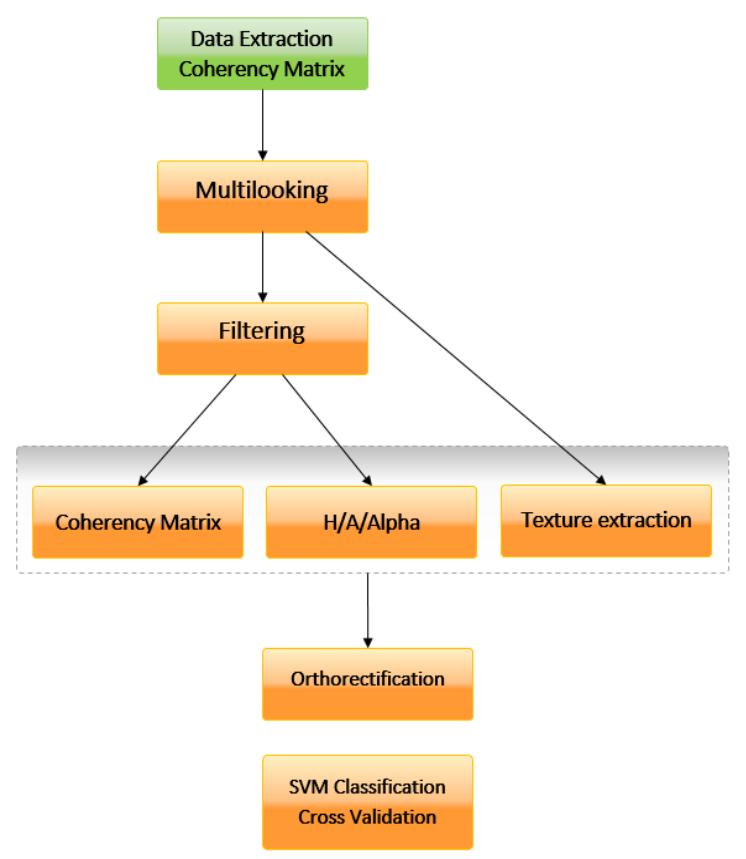

Fig. 3. Radar data processing procedure 


\section{B. LiDAR methodology}

The fundamental concept of a LiDAR measurement is to send a laser pulse towards a target and to measure the time and amount of energy that is scattered back from the target. For each laser pulse emitted, the instrument measures the time the wave takes to make the two-way displacement up to the target object. In the atmosphere $(n=1)$, the laser wave displacement with the velocity of light $(\mathrm{c}=3 \times 108 \mathrm{~m} / \mathrm{sec})$, the two-way displacement duration $(\tau)$ is converted into distance between the instrument and the target $(\rho)$ by means of the equation formula:

$$
\rho=\frac{c}{n} \frac{\tau}{2}
$$

The instrument position, laser pulse emission direction and two way displacement distance of the wave allow for accurate localization in space of the target surface and therefore, for the determination of its altitude. Given that LiDAR emits, in general, between 10000 and 30000 pulses per second [69], it is possible to measure the terrain elevation with a large number of points, having a density of $0.1-5$ points per $\mathrm{m}^{2}$ of soil [74], [75] but which can be higher if required. An interpolation, i.e., the determination of the unknown values derived from the neighboring values, allows for the altitude to be obtained on a regular grid based on point seeding. The result is presented in the form of a pixel matrix with each pixel having an altitude value. This format is simpler and more practical for calculation and visualization purposes than point seeding.

The LiDAR sensor emits a pulse in the near infrared. The first return only records the position of the first object (top of the canopy, roof, etc.); however, the last return indicates the height of the last objet, which corresponds, depending on the data acquisition conditions and the density of the canopy, to the soil or vegetation [76]. Soil height can be calculated directly using the points of the first return, whereas the classification of the pulses from the last returns is necessary to discriminate between the points characterizing the low- or intermediategrowing vegetation layers and the points representing soil [77]. The surface covered by a pulse, called a footprint, corresponds to a circle approximately $20-30 \mathrm{~cm}$ wide [78]. The pulse can be reflected by several surfaces located within this circle, generating several echoes. This happens mainly at the vegetation level and in the building limits. For instance, during the acquisition of LiDAR data over a forest area, a portion of the pulse is reflected by the vegetation while the remainder passes through it before being reflected by the soil. Each target hit by the wave corresponds to an echo, which allows distinguishing the structures located below the vegetal cover. This phenomenon appears if the targets are distant enough from one another; otherwise, there is an overlap of the two echoes and they can no longer be distinguished. Vegetation height is a function of species composition, climate and site quality and can be used for land cover classification [3]. The height classes were obtained by a multi-thresholding segmentation using the Quantum GIS software (QGIS) for imaging height measurements (Fig. 6).
C. SPOT-5 methodology (Calibration of the SPOT-5 optical data using in situ spectral measurements)

In the first part of this methodology, we preprocessed the SPOT image; the image calibration can be compared to a range of spectral field measurements of the main land cover classes. This calculation is possible in the three bands since the radiometer only records measurements in the visible and near infrared wavelengths (B1: green, B2: red, B3: NIR). We chose seven spectroradiometric measurement points for each of the three spectral bands.

The sensors used in remote sensing are radiometers that measure the luminance reflected simultaneously by the Earth and the atmosphere. Therefore, the radiometric signal depends on the reflectance of the Earth's surface, the incident illumination and atmospheric effects. In this paper, we applied a method using field spectroradiometric measurements on reference points that can be identified in the image (Fig. 4).

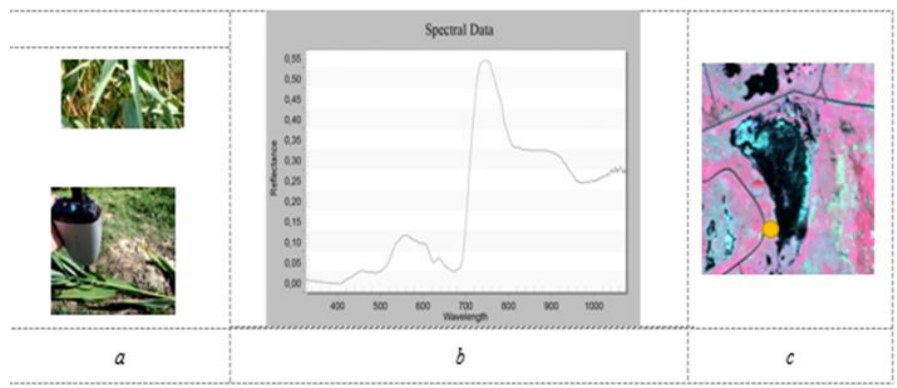

Fig. 4 (a) Measure of the reflectance of Phragmites australis

(b) Spectral curves of Phragmites australis

(c) Localization of Phragmites australis on the SPOT-5 image

The reflectance values were obtained through the relationship y $=\mathrm{a} . \mathrm{x}+\mathrm{b}$, where $a$ and $b$ are the two coefficients of regression between the image values and the field measurements (Fig. 5). The image pixel luminance values can then be converted into reflectance by means of linear extrapolation. The figure shows the regression lines obtained by connecting the image pixel luminance values on the B1, B2 and B3 bands (the three spectral bands of SPOT-5) with the seven points measured on site by a spectroradiometer. As can be noted (Fig. 5. (a), (b) and (c)) the correlation between the two variables was strong. Consequently, the values of the coefficients of determination $\left(\mathrm{R}^{2}\right)$ were very good. For the data calibration, we used the ENVI 5 (Classic) software (Spectral/ Preprocessing/ Calibration Utilities). 


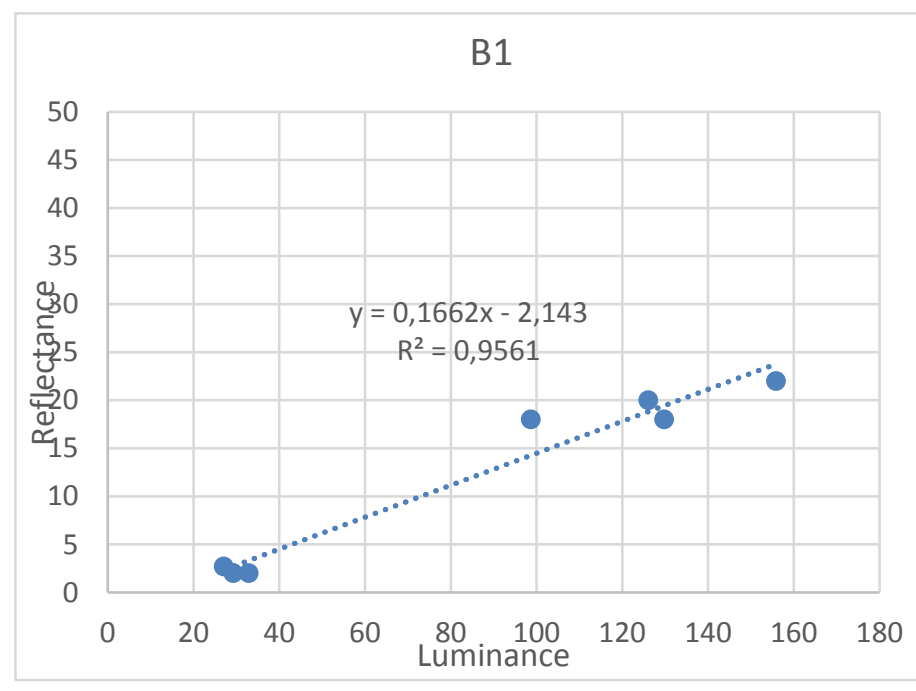

Fig. 5 (a) Correlation between the luminance values of image band 1 and the reflectance measured in situ for the seven points

B2

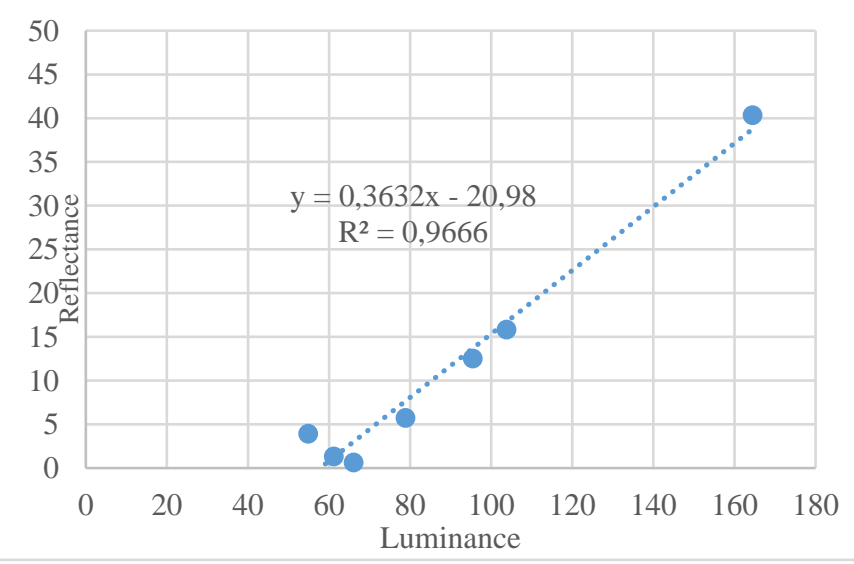

Fig. 5 (b) Correlation between the luminance values of image band 2 and the reflectance measured in situ for the seven points

\section{B3}

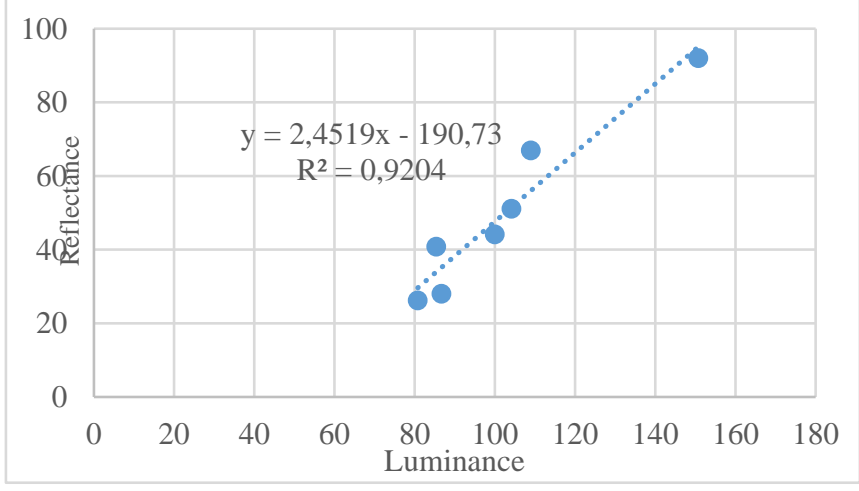

Fig. 5. (c) Correlation between the luminance values of image band 3 and the reflectance measured in situ for the seven points.

\section{Support Vector Machine (SVM) methodology}

To compare the discrimination capabilities of the different sensors used in this paper, we chose to use the SVM supervised classification algorithm. This algorithm was applied to all of the data in the study.

The algorithm preferred for our research was the SVM because it allows for non-linear classification. The algorithm can contain several parameters, which is often necessary to achieve high classification accuracy with radar data. Furthermore, its non-parametric nature is well suited for SAR image classification (and derived parameters) of various statistical distributions. The support vectors are essential components of the learning stage and their selection partly depends on a penalty parameter that allows for varying degrees of information bias, which is particularly important for the class samples that are not entirely separable during the learning stage. The learning stage of SVM also relies on the kernel concept. This consists in using a linear classifier to solve a nonlinear problem by extending the input data representation space and then using a linear classifier. The choice of the kernel function to achieve this transformation is important and there are several types of kernels, namely linear, radial basis function (RBF), polynomial and sigmoid kernels. With respect to radar image classification, an RBF kernel was used for the SVM classifications described in the results. The SVM principle was developed for a two-class problem but can easily be extended to a multi-class problem by considering, for example, the "One Against All" (OAA) or the "One Against One" (OAO) algorithms. If the $K$ classes are considered, the OAA algorithm consists in the construction of $K$ hyperplanes that separate one class from the $K-1$ other classes. The OAO algorithm consists in the construction of $K(K-1) / 2$ hyperplanes, which separate each pair of classes. The OAO algorithm was retained for this application. We chose the RBF kernel due to its ability to solve non-linear problems but also because it requires only one parameter, the Gamma parameter, in addition to the cost parameter common to every kernel. Finally, in order to optimize the cost and gamma parameter, we used a cross-validation in grid search processing. Therefore, for every classification we previously found the best cost and gamma couple. The calculations for SVM were carried out on the SVM Library of the Orfeo Toolbox.

For more details on processing procedure of SVM, see reference [79].

\section{E. Multisensor data integration}

The final stage of the image processing relates to the integration of several images from two satellites (RADARSAT2, SPOT-5) and LiDAR, which have different spatial resolutions. Image integration is a method for combining information from various sources. Consequently, using a combination of different sensors, we resampled the data to the smallest pixel size between optical and radar. All the datasets were orthorectified and resampled to a $5 \mathrm{~m}$ pixel size and separately classified.

\section{Mapping validation}

The detailed vegetation map of the Caraorman area shown in the next part of the paper was validated using 
vegetation transects. Classification accuracy was assessed using global and Kappa indices. More than 100 transects were carried out over the Caraorman region and allowed to derive a detailed vegetation map. This map was simplified to be compatible with those that we produced from remote sensing images. Reference data were collected in June and July 2011. Selected areas were visited in situ and the vegetation cover was identified. The classification accuracy was estimated using cross-validation and by calculating the percentage of correctly classified pixels on the resulting maps. The resulting distribution maps were validated with expert knowledge and with additional field visits for the interpretation of potentially misclassified areas. The ground reference data consisted of 160 samples, covering 12 vegetation types.

Simultaneously, the heights of most of the vegetation classes were measured in the field (Ground Control Point measurements (GCP)) and compared to the LiDAR estimates. The survey by point has been chosen. The choice of training and control point sets is the result of a stratified random sampling (with software ENVI 4.8). 500 training points and 800 control points are set for all classes. The random survey is stratified from the thematic areas homogeneous (class of height of vegetation). The stratification was conducted, in a first time before the phase of measures in the field. In the field we also used a system of positioning by satellite of type GPS (Global Positioning System) for all points. The points have been examined in the field (between 50 and 60 by the class of height of vegetation). Strong correlation between measured and estimated heights over all vegetation types was found $\left(R^{2}=\right.$ 0.95 , RMSE $=0.35$ ). These statistical indicators have been calculated with software R.

Mapping accuracies were summarized using confusion matrices and statistics including user, producer and overall accuracy and Cohen's K [80]. Overall accuracy is the percentage of correctly classified points from the ground dataset. The statistical criteria were based on the confusion matrix created from a comparison between the classification and the verification data. Generated from this confusion matrix, the percentage of Pixels Correctly Classified (PCC) and the Kappa coefficient of agreement (k) [81] were analyzed to assess class discrimination. The Kappa coefficient takes into account the expected agreement and is therefore considered to be a better single classification accuracy measure [82]. The maps had strong Kappa indices ( 0.80 for the SPOT classification; 0.49 for RADARSAT-2; 0.91 for SPOT/LiDAR; 0.69 for RADARSAT-2/LiDAR; 0.83 for SPOT/RADARSAT-2; and 0.89 for SPOT/LiDAR/RADARSAT-2) indicating strong agreement between the classifications and observed vegetation classes. To obtain more data, the vegetation cover was also photographed along airborne transects.

\section{RESUlTS}

Vegetation in the study region and, in Danube Delta in general, is highly mixed, both within and between vegetation types. Our results relate to combinations of data from different satellite sensors (SPOT-5, RADARSAT-2 and LiDAR) in order to improve the accuracy of recognition and mapping of major vegetation classes in the Danube delta. First, the data from each sensor are classified and analyzed. Results show medium classification performance $(78.07 \%$ mean accuracy for the SPOT image classification; $51.89 \%$ for the radar image classification) in this first step. The combination of SPOT-5 data and radar data improved the performance of the classification $(83.81 \%)$ and the combination of the three types of data provides an excellent performance for the multi-sensor classification $(90.60 \%)$.

\section{A. Detection and mapping of vegetation based on LiDAR measurements}

The vegetation was classified into seven classes associated with the seven following layers (Fig. 6): "low grass layer" class lower than $20 \mathrm{~cm}$; "middle sedge layer" class, ranging between $20 \mathrm{~cm}$ and $1 \mathrm{~m}$; "reed layer" and "shrub layer" class, ranging between $1 \mathrm{~m}$ and $2.5 \mathrm{~m}$; "tree layer" class at $25 \mathrm{~m}$ and "water" class at $0 \mathrm{~m}$. The LiDAR-determined vegetation heights were correlated to those measured in the field.

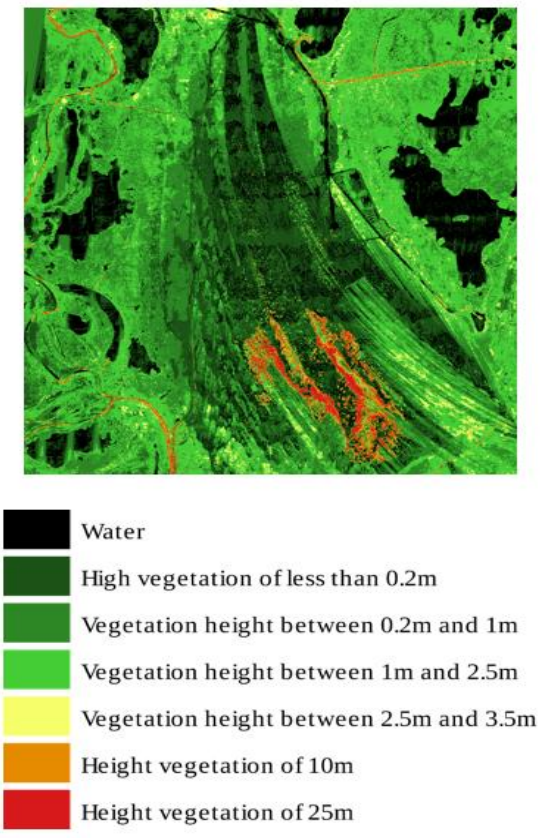

Fig. 6. LiDAR classification: vegetation height in the Caraorman region

The height and density of our delta vegetation vary (table 2).

TABLE 2

CLASS COMPOSITIONS HEIGHT VEGETATION

\begin{tabular}{|c|c|}
\hline Height vegetation & Composition \\
\hline $10 \mathrm{~m}-25 \mathrm{~m}$ & $\begin{array}{l}\text { Populus alba, Fraxinus pallisiae, Malus } \\
\text { dasyphylla, Quercus pedunculiflora }\end{array}$ \\
\hline $2.5 m-3.5 m$ & $\begin{array}{l}\text { shrubs : Rubuscaesius, Cornus sanguinea and } \\
\text { Amorpha fruticose }\end{array}$ \\
\hline $1 \mathrm{~m}-2.5 \mathrm{~m}$ & $\begin{array}{l}\text { Typha angustifolia and Latifolia, Carex sp., } \\
\text { Phragmites australis }\end{array}$ \\
\hline $0.2 \mathrm{~m}-1 \mathrm{~m}$ & Sedge subspecies \\
\hline $0.2 \mathrm{~m}$ & $\begin{array}{l}\text { Puccinellie and Limnonium gmelinii, Carex } \\
\text { colchica, Ephedra distachya, Elymus } \\
\text { giganteus, Festuca beckeri }\end{array}$ \\
\hline
\end{tabular}

Vegetation height mapping relying on LiDAR data can be used to identify vegetation layers (grasses, reeds, shrubs and trees). 
However, these images did not enable us to characterize plant formations within each of these layers. We suggest additional information sources, namely a SPOT-5 image acquired on May 2011 and a RADARSAT-2 radar image acquired on June 4, 2011; we also suggest a data integration series between these three types of data, SPOT/Radar, SPOT/LiDAR and SPOT/Radar/LiDAR, as shown in Fig. 10.

\section{B. Detection and mapping of vegetation based on SPOT-5 image processing}

The SPOT image covers the visible and near infrared spectral ranges, which are two strategic ranges used for identifying vegetation. The multispectral sensor enabled us to detect the spectral responses of each plant formation (Fig. 7). The median signature of the vegetation is the mixed contribution of the substrate and the vegetation.

Vegetation types were labeled following 12 classes (Table 3 ). This classification allowed us to distinguish 5 classes of reeds in the large marsh vegetation class (pure reed vegetation, reed vegetation on compact reed, reed vegetation on open plaur, reed vegetation and bushes on compact plaur, mixed reed vegetation).
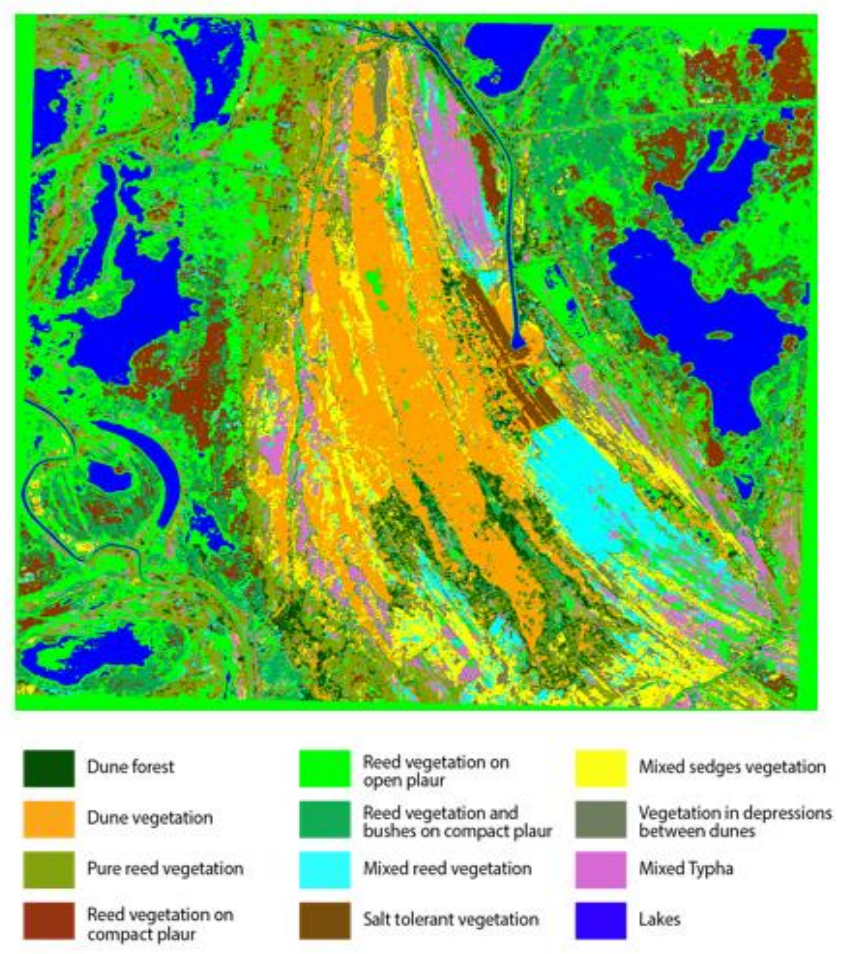

Fig. 7. SPOT-5 classification: 12 land cover classes

TABLE 3

CLASS COMPOSITIONS

\begin{tabular}{|l|l|l|l|}
\hline Class & Composition & Class & Composition \\
\hline
\end{tabular}

\begin{tabular}{|c|c|c|c|}
\hline Dune forest & $\begin{array}{l}\text { Broadleaf trees : Alnus } \\
\text { glutinosa, Populus alba, } \\
\text { Fraxinus pallisiae, } \\
\text { Fraxinus angustifolia, } \\
\text { Malus dasyphylla, } \\
\text { Quercus pedunculiflora }\end{array}$ & $\begin{array}{l}\text { Mixed reed } \\
\text { vegetation }\end{array}$ & $\begin{array}{l}\text { The dominant species is } \\
\text { Phragmites australis, } \\
\text { usually accompanied by } \\
\text { a hygrophilous species } \\
\text { such as Typha } \\
\text { angustifolia, } \\
\text { Schoenoplectus } \\
\text { lacustris, and } \\
\text { Sparganium erectum, } \\
\text { Thelypteris palustris }\end{array}$ \\
\hline $\begin{array}{l}\text { Dune } \\
\text { vegetation }\end{array}$ & $\begin{array}{l}\text { Carex colchica, } \\
\text { Ephedra distachya, } \\
\text { Elymus giganteus, } \\
\text { Festuca beckeri, } \\
\text { Ephedra distachya, } \\
\text { Secale silvestre, } \\
\text { Centaurea arenaria, } \\
\text { Elymus giganteus } \\
\end{array}$ & $\begin{array}{l}\text { Salt } \\
\text { tolerant } \\
\text { vegetation }\end{array}$ & $\begin{array}{l}\text { Puccinellio- } \\
\text { Salicornietum, } \\
\text { Puccinellietum limosae, } \\
\text { Puccinellia convoluta, } \\
\text { Limonium gmelinii, } \\
\text { Juncus maritimus, } \\
\text { Aeluropus littoralis. }\end{array}$ \\
\hline $\begin{array}{l}\text { Pure reed } \\
\text { vegetation }\end{array}$ & Phragmites australis & $\begin{array}{l}\text { Mixed } \\
\text { sedges } \\
\text { vegetation }\end{array}$ & $\begin{array}{l}\text { A great number of } \\
\text { Danube delta reed types } \\
\text { and subtypes fit under } \\
\text { the classification of } \\
\text { Scirpo-Phragmitetum } \\
\end{array}$ \\
\hline $\begin{array}{l}\text { Reed } \\
\text { vegetation } \\
\text { on compact } \\
\text { reed }\end{array}$ & Phragmites australis & $\begin{array}{l}\text { Vegetation } \\
\text { in } \\
\text { depressions } \\
\text { between } \\
\text { dunes }\end{array}$ & $\begin{array}{l}\text { Salix rosmarinifolia, } \\
\text { Quercus pedunculiflora, } \\
\text { Fraxinus pallisae }\end{array}$ \\
\hline $\begin{array}{l}\text { Reed } \\
\text { vegetation } \\
\text { on open } \\
\text { plaur } \\
\end{array}$ & Phragmites australis & $\begin{array}{l}\text { Mixed } \\
\text { Typha }\end{array}$ & Scirpo-Phragmitetum \\
\hline $\begin{array}{l}\text { Reed } \\
\text { vegetation } \\
\text { and bushes } \\
\text { on compact } \\
\text { plaur }\end{array}$ & $\begin{array}{l}\text { Salix cinerea, Amorpha } \\
\text { fruticosa }\end{array}$ & & \\
\hline
\end{tabular}

The SPOT-5 image classifications (Fig. 7) (78.07\% mean accuracy) have satisfactory overall accuracy. The classification precision analysis per class proves that the SPOT-5 image classifications allow for the identification of all of the classes (12 classes). The following classes exhibit satisfactory accuracy: pure reed vegetation $(75.5 \%)$, dune vegetation (95.2\%), reed vegetation on open plaur (floating vegetation called plaur (floating reed bed) is an association of reeds and other wetland plants that grow on a one-meter thick cover made up of roots, soil and various organic materials) (90\%) and salttolerant vegetation $(81.8 \%)$. Mixed sedge vegetation (57.8\%), dune forests $(47.8 \%)$ and reed vegetation and bushes on compact plaur classes exhibited lower performance in the mapping results. As far as the pure reed class or the vegetation in depressions between dunes class is concerned, the reed beds were relatively well identified. There was some confusion between the mixed sedge vegetation and mixed Typha classes. The spatial resolution of the sensor $(10 \mathrm{~m} \mathrm{x} 10 \mathrm{~m}$ in the multispectral mode) did not allow for the discrimination of the various plant formations in environments that were too heterogeneous, such as mixed reed or mixed Typha. The SPOT5 spatial resolution $(10 \mathrm{~m})$ did not allow for mapping the smallest components of the delta landscape, such as the delta lake macrophytes.

The classification of vegetation types based only on their spectral characteristics involves different constraints. Within a single pixel, vegetation often consists of a mixture of species. 
Additionally, the boundaries between the patches of different vegetation types often occur as smooth transitions rather than sharp edges [83]. The reflectance spectra of wetland vegetation canopies are often very similar and are combined with reflectance spectra of the underlying soil, hydrologic regime and atmospheric vapor [84], [85], [86]. Current efforts, which have been successful at mapping terrestrial vegetation using optical remote sensing, may not be able, either spatially or spectrally, to effectively distinguish the flooded wetland vegetation because of the performance of near to mid-infrared bands that are attenuated by the occurrences of underlying water and wet soil [87], [88]. Landsat TM and SPOT imagery have proven insufficient for discriminating vegetation species in detailed wetland environments [89], [90]. More complicated mapping tasks require other data sources such as LiDAR and radar.

\section{Detection and mapping of vegetation based on RADARSAT-2 image processing}

Polarimetric radar data are sensitive to substrate roughness and moisture. Non-dominant double-bounce backscattering characterizes the first plant growth stage (May-June). This mechanism continues to dominate until July-August (the maturity phase for most of the Danube delta species). Therefore, the beginning of summer is the best time for vegetation structure classification and the end of summer (end of July through the beginning of September) is the best time for their characterization, for instance, to undertake aboveground biomass estimation.

The classification accuracy of the radar image (Fig. 8) acquired on June 4, 2011 was estimated to be $51.89 \%$, which was inferior to that of the SPOT image, with a very low mean accuracy.
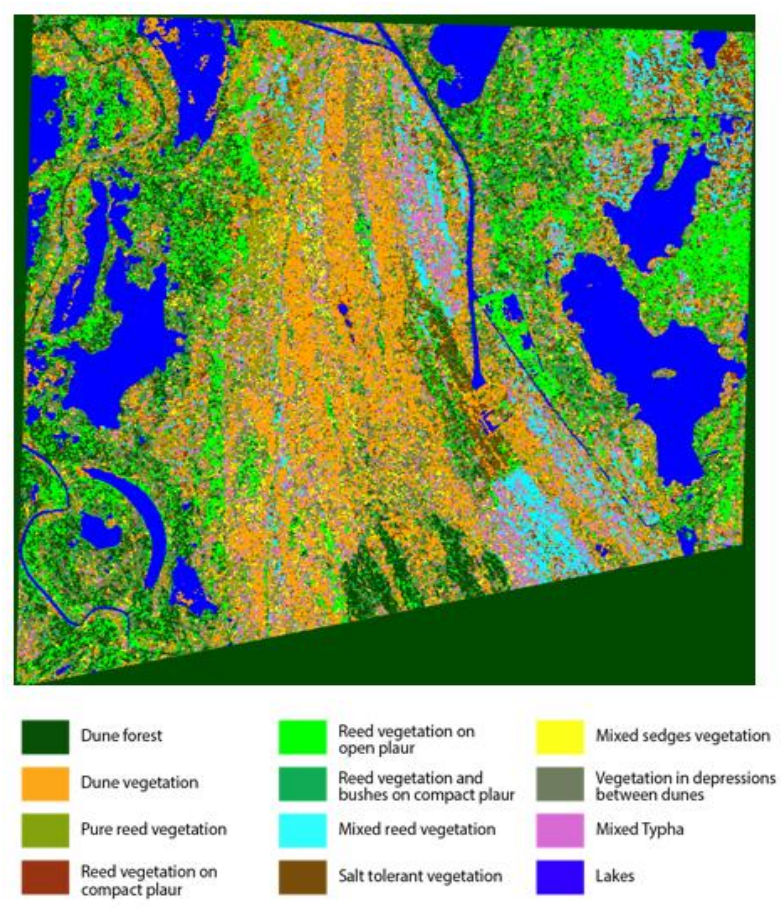

Fig. 8. RADARSAT-2 classification: 12 land cover classes
The clearly identified classes are dune forests (78\%), dune vegetation $(65.4 \%)$, bodies of water (lakes) and vegetation in depressions between dunes. There was some confusion between similar vegetation classes (pure reed vegetation, reed vegetation on compact reed, reed vegetation on open plaur, reed vegetation and bushes on compact plaur, mixed reed vegetation and mixed sedge vegetation). Classes associated with the tree layers are well characterized. The partial distinction between the reed beds allows for the identification of homogeneous plant formations within the same mixed class.

Polarimetric signatures were suggested for all of the classes (Fig. 9) in order to better identify and characterize the twelve classes.
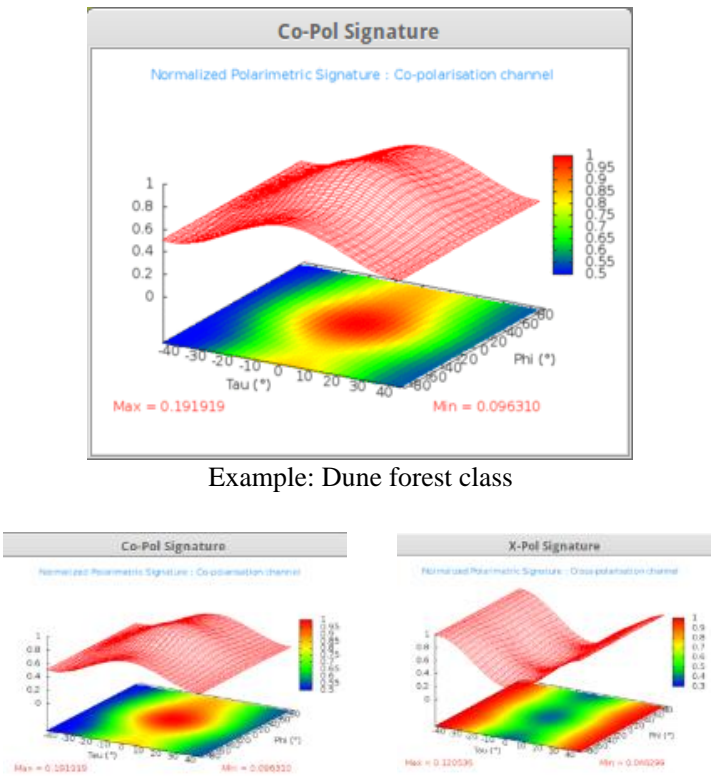

(a) Dune forest class

Fig. 9. Polarimetric signatures, Dune forest classe (example)

Polarimetric signatures show the backscattering response of a target (Figure 9). The polarimetric signature of a pixel on a signature image of the elementary targets already determined can be used to consequently deduce the type of scattering present. The purpose is to establish a link between the physical characteristics of the various targets analyzed and the backscattering mechanisms. The polarimetric information of a target reflects the biophysical features and the geometric structure of the latter. Results of this analysis show that reed classes have similar polarimetric signatures. Similar polarimetric signatures are reported between Typha and sedges. In the spring, Typha sites are characterized by surface backscattering. Typha species have medium and strong foliar biomass and are characterized by long, rather large and ordered leaves (often upright and rigid). Stem diameter is close to the C-band wavelength. Phragmites australis has medium and strong foliar biomass and is characterized by long, rather narrow and disordered leaves. Stem diameter is smaller than the C-band wavelength. Carex species have low foliar biomass and the diameter of their upright stems is smaller than the C-band wavelength. 
Higher species $(>1 \mathrm{~m})$ with greater biomass do not have a specific structure. In principle, the long, narrow and disordered leaves of these species should enhance volume backscattering (Fig. 9 (a)). The most specific element of these backscattering operations is the presence of a double-bounce component in the spring when the water level is high (for swamp shrubs). In the spring (May and beginning of June), swamp detection is often based on their strong signal, especially in $\mathrm{HH}$ polarization, due to the occurrence of double bounce backscattering due to water [91], [35]. The radar backscattering coefficient normally diminishes with plant water content reduction [91]. Moreover, soil moisture is better and more accurately detected by radar images than by visible and near infrared images because radar data provide information about the water content of the first 10 $\mathrm{cm}$ of bare or minimally covered soil [92].

D. Detection and mapping of vegetation based on the synergy between LiDAR, RADARSAT-2 and SPOT-5 images

To better understand and characterize the spatial organization of Danube delta vegetation (in the Caraorman area) and to provide a synthetic view of the dynamics of this environment, optical remote sensing (SPOT), altimeter (LiDAR), radar (RADARSAT-2) and field observation data were acquired and processed together.

By integrating the SAR data with optical images such as SPOT, the quality of the habitat maps (Fig. 10 (a)) can be considerably improved. Data integration between the SPOT and RADARSAT-2 images provides classification with an overall accuracy of $83.81 \%$ and satisfactory class accuracies ranging between $68.2 \%$ and $92.9 \%$, except for the lake class (100\%). The dune vegetation (92.9\%), mixed Typha (91.8\%), reed vegetation on open plaur $(91.5 \%)$, salt-tolerant vegetation $(85.6 \%)$, mixed reed vegetation $(85.6 \%)$ and dune forest $(82.8 \%)$ classes were well mapped and show good accuracy.

Individually, SAR and SPOT imagery had poor accuracy when mapping three land cover categories (open water, flooded vegetation and non-flooded land), but the RADARSAT-2 and SPOT combination contributed complementary data that produced significantly better classification results [34].

Moghaddam et al. (2002) [93] found that combining Landsat TM and different radar data was more accurate for predicting ground-based measurements of forest structure than any sensor alone. Slatton et al. (2001) [64] combined LiDAR data with interferometric radar data to improve estimates of vegetation heights.

Results were considerably improved by integrating SPOT, radar and LiDAR data (Fig. 11), with overall accuracy reaching $90.60 \%$ (table 4). The dune forest $(97.6 \%)$, salt-tolerant vegetation $(96.2 \%)$, reed vegetation on open plaur $(94.1 \%)$, mixed reed vegetation $(92.1 \%)$, vegetation in depressions between dunes (93.6\%) and mixed Typha (95.2\%) classes were well identified.
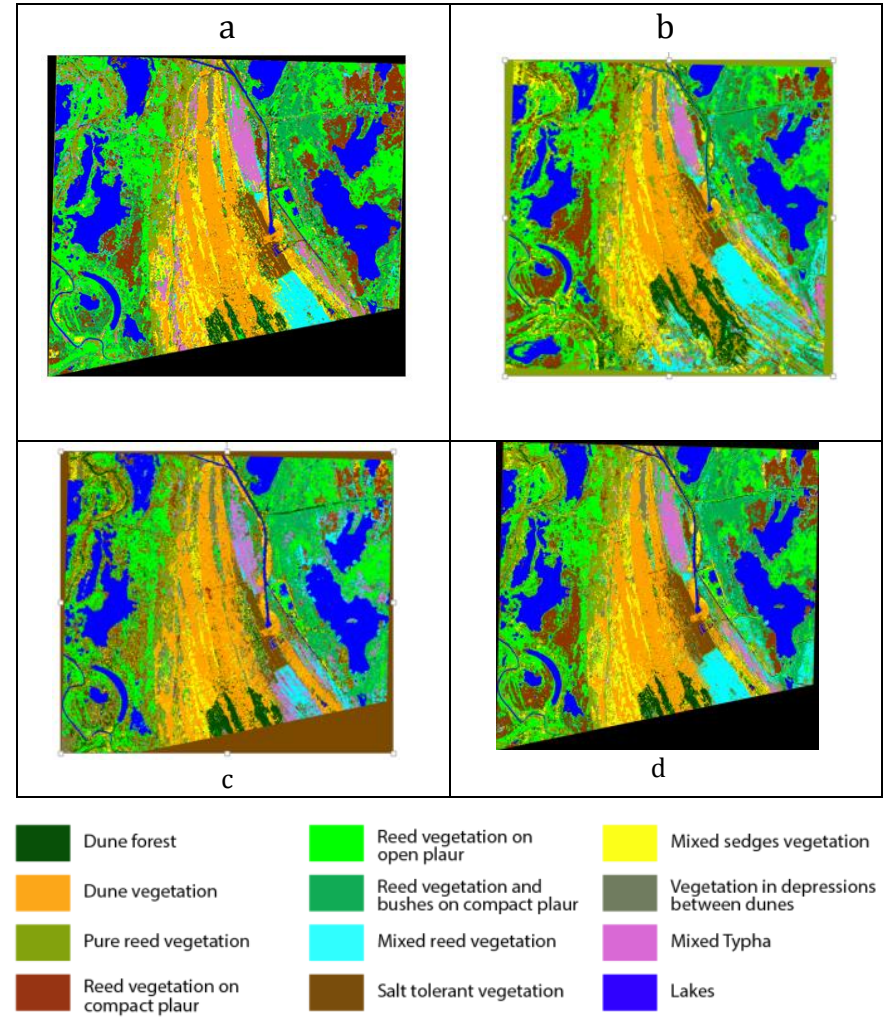

Fig. 10. a) Data integration: optical image/radar image

b) Data integration: optical image/LiDAR

c) Data integration: radar image/LiDAR

d) Data integration: optical image/radar image/LiDAR.
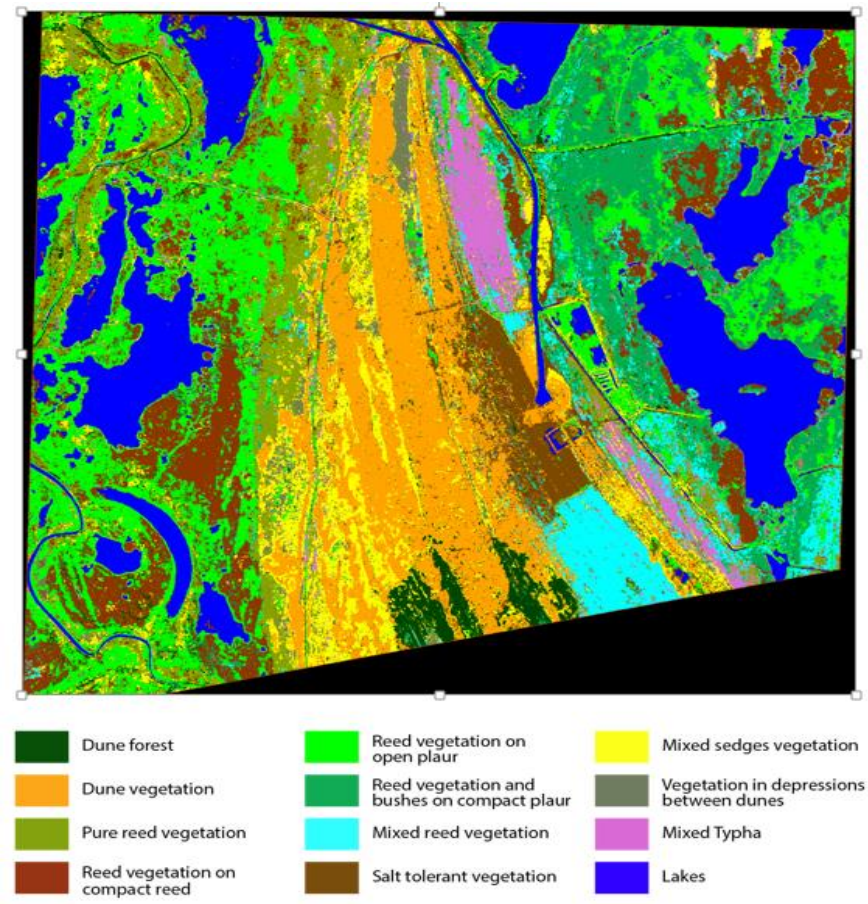

Fig. 11. Multi-sensor data integration: SPOT-5, LiDAR and RADARSAT-2: 12 land cover classes

TABLE 4

MEAN ACCURACY OF SPOT-5/RADARSAT-2/ LIDAR MULTI-SENSOR DATA INTEGRATION 


\begin{tabular}{cccc}
\hline \hline Class & $\begin{array}{c}\text { Prod. Acc. } \\
\text { (Percent) }\end{array}$ & Class & $\begin{array}{c}\text { Prod. Acc. } \\
\text { (Percent) }\end{array}$ \\
\hline Dune forest & 97.6 & $\begin{array}{c}\text { Reed vegetation and } \\
\text { bushes on compact } \\
\text { plaur }\end{array}$ & 89 \\
Dune vegetation & 94.5 & $\begin{array}{c}\text { Mixed reed } \\
\text { vegetation }\end{array}$ & 92.1 \\
$\begin{array}{c}\text { Pure reed } \\
\text { vegetation }\end{array}$ & 78.8 & $\begin{array}{c}\text { Salt tolerant } \\
\text { vegetation }\end{array}$ & 96.2 \\
$\begin{array}{c}\text { Reed vegetation } \\
\text { on compact plaur }\end{array}$ & 81.5 & $\begin{array}{c}\text { Mixed sedge } \\
\text { vegetation }\end{array}$ \\
$\begin{array}{c}\text { Reed vegetation } \\
\text { on open plaur }\end{array}$ & 94.1 & $\begin{array}{c}\text { Vegetation in } \\
\text { depressions } \\
\text { between dunes }\end{array}$ & 93.6 \\
Lakes & 100 & Mixed Typha & 95.2 \\
\hline
\end{tabular}

Mean Accuracy

$90,60 \%$

\section{DISCUSSION}

Combinations of spaceborne SAR imagery and SPOT image and LiDAR were evaluated.

We analyzed the potential and limitations of LiDAR, RADARSAT-2 and SPOT-5 data and their integration for the recognition and characterization of the main vegetation classes in the Caraorman region of the Danube delta. The vegetation map provides an understanding of the distribution of vegetation patterns.

LiDAR is an active remote sensing technology that can provide accurate vertical vegetation structural parameters. Results revealed that the altimetric accuracy of the LiDAR data allowed for the characterization of vegetation height with an accuracy of $10 \mathrm{~cm}$. The heights were measured in the field and compared to the LiDAR estimates. However, the LiDAR data containing spectral information only in the near infrared band did not allow for distinguishing between the various plant formations within the same layer. When acquired in a coastal marsh environment, the research demonstrated a decreased ability for the laser pulse to penetrate through the vegetative layer onto the ground surface [14]. Because of the poor penetration of the laser pulse through the marsh vegetation (few ground points are available because of water absorption), bareearth LiDAR elevations can be markedly less accurate (pure reed vegetation $31.20 \%$, reed vegetation on compact plaur $19.42 \%$, mixed reed vegetation $30.10 \%$, mixed sedge vegetation $33.13 \%$ ) when compared with adjacent upland habitats (dune forest $84.31 \%$, dune vegetation $95.17 \%$ ).

Therefore, by linking multispectral, LiDAR and radar data, it is possible to obtain information about vegetation reflectance and height as well as the backscattering mechanism, which allows mapping and characterization accuracy refinement.

Certain types of wetlands were more easily distinguished on the satellite images than others for a number of reasons. First, classes such as partially forested lowlands exhibited varying degrees of heterogeneity. It is difficult to accurately estimate the mix of trees, shrubs and herbaceous plants, and so the dominant type was easily misassigned.
The SPOT-5 scene resolution provided an adequate scale for acquiring detailed field data within homogeneous stands, allowing for optimization of the time spent for data collection and the proper localization of the sampled plots on the ground and on the scenes. Passive data do not allow for automatic characterization of all plant formations. We were able to identify certain plant formations automatically due to their strong spectral singularity. This is the case with pure reed or dune vegetation areas. Therefore, "homogeneous" habitats, such as reed beds, may be identified based on SPOT-5 images. Heterogeneous plant formations, rather common in these wetlands, are not always identifiable and rarely extractible from this type of image. Our results also highlight the advantage of associating simultaneously acquired multispectral SPOT-5 images and LiDAR data to improve heterogeneous and complex habitat maps (mean accuracy of $92.4 \%$, table 5). When integrated with optical data, the LiDAR data collected over the Danube delta constitute an extraordinary database for use as a starting point to understanding vegetation organization in the delta.

Radar data have the capability of penetrating the plant cover canopy and detecting submerged sectors and soil surface moisture. Although the spatial resolution of these images does not allow thorough and detailed habitat mapping, our results revealed the usefulness of these images for mapping wetland vegetation. Our results prove that radar polarimetry (and polarimetric parameters) contributes significantly to the improvement of vegetation identification based on polarization channels.

The integration of radar and optical data (83.81\%) considerably improves the performance of wetland identification and characterization. There are good complementarities between SPOT-5 surface discrimination and SAR vegetation density information (table 3 ).

TABLE 5

COMPARISON OF THE MEAN ACCURACY OF THE DIFFERENT SENSORS

\begin{tabular}{cc}
\hline \hline Sensors & Mean accuracy (\%) \\
\hline SPOT & 78.07 \\
RADARSAT-2 & 51.89 \\
LiDAR & 58.26 \\
SPOT/RADARSAT-2 & 83.81 \\
SPOT/LiDAR & 92.64 \\
RADARSAT-2/LiDAR & 73.28 \\
SPOT/RADARSAT-2/LiDAR & 90.60 \\
\hline \hline
\end{tabular}

Following are a few examples indicating how these results are consistent with the results from other research in the field.

Trios of data sets (RADARSAT-1, Landsat-7 ETM+ and DEM data) were used to help map wetlands in eastern Canada 
into five classes [11]. The wetland classes, along with their corresponding accuracies were as follows: open bog 92\%; marsh 84-89\%; swamp 79\%; and open fen $83 \%$.

The synergy of combining SAR data with optical images for coastal land cover mapping was investigated by Henderson et al. (2002) [94]. In this study, wetland categories consisted of estuarine emergent, palustrine emergent, palustrine shrub and palustrine forested areas. The incident angle was less important here than the spatial resolution; the fine mode image merge produced the best results. No merge combination produced acceptable operational (ca. 85\%) wetland mapping accuracies, although merging the SAR with TM data did improve the results.

Allen et al. (2013) [65] obtained the following results: the highest overall accuracy used SAR, LiDAR canopy and digital elevation model (DEM) data $(81 \% \kappa=0.744)$, but was not significantly different from the SAR-only classification $(81 \% \mathrm{~K}$ $=0.742$ ). Both classifications exceeded the data combination of SAR data with DEM $(66 \% \kappa=0.521)$ and SAR data with vegetation canopy data $(80 \% \kappa=0.725)$.

Maxa M. and Bolstad P. (2009) [66] compared the accuracy of the Wisconsin Wetland Inventory maps to maps derived from IKONOS high resolution satellite data and LiDAR data: IKONOS/LiDAR data were significantly more accurate ( $74.5 \%$ classification accuracy).

Another example of improving classification accuracy by incorporating vegetation-related environmental variables using GIS with remotely sensed data is the work of Yang (2007) [95] in the Hunter region of Australia. He used digital aerial photographs, SPOT-4 and Landsat-7 ETM+ images for riparian vegetation delineation and mapping. The overall vegetation classification accuracy was $81 \%$ for digital aerial photography, $63 \%$ for SPOT-4 and 53\% for Landsat-7 ETM+.

Results of the research presented in this article show accuracy of mapping of vegetation habitats greater than the previous research. Thus, the method of multi-sensor data integration is a method that improves the accuracy of mapping the vegetation habitats in the Danube delta.

The temporal aspect, in addition to the spectral and spatial characteristics, is a valuable source of information in relation to the monitoring and management of plant resources and to the monitoring of the land cover dynamics. Hydrology, in terms of speed of flood, has an important role in the vegetation distribution in the Danube delta. The temporal aspect could be very interesting for a future study. The synergy of multitemporal satellite data could constitute a useful methodology for wetland mapping and characterization using the relationship between the distribution of vegetation formations and flood duration. The objective would be to achieve, on the one hand, the observation of plant dynamics in relation to the main flooding periods in the delta and, on the other hand, the monitoring of wetlands during the growing seasons to assess the phenological variability of the major plant species.

\section{CONCLUSION}

Wetland extent and type may change due to variations in land use, hydrological conditions or vegetative successions, requiring update information on the main classes of land cover. Incomplete or inaccurate maps limit our ability to recognize and map wetland conditions and losses and to develop effective policies for wetland management. Because of the synthetic view that it provides, remote sensing is an important and effective tool for conducting large inventories/recognition of wetlands at a regional scale and at regular intervals. Remote sensing contributes to the state of knowledge through the understanding of the interactions between the optical signal, the polarimetric radar signal, LiDAR measurements and wetland environment in the Danube delta.

Wetland vegetation plays a key role in the ecological functions of wetland environments. Vegetation characterization was applied in the wetlands of the Caraorman region of the Danube delta based on several types of remote sensing data, enabling us to perform a comparative assessment of these data. Results support the importance of the joint use of several data types (Fig. 12).

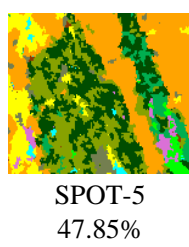

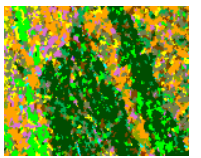

RADARSAT2 $78 \%$

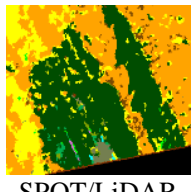

SPOT/LiDAR $95.90 \%$

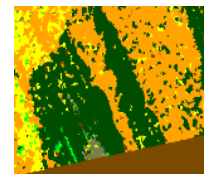

RADAR/LiDAR

$82.77 \%$

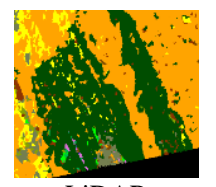

LiDAR $83.31 \%$

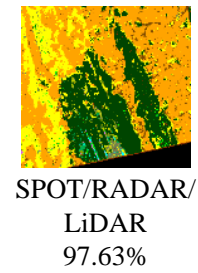

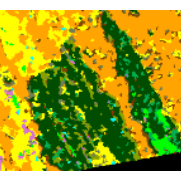

SPOT/RADAR $82.77 \%$
Fig. 12. Classification examples of the dune forest class by sensor and corresponding accuracy

LiDAR provides reliable results (mean accuracy higher than $80 \%$ ) for dune forests, dune vegetation and mixed Typha detection; radar data are well suited for dune forest detection; optical data are perfect for dune vegetation, reed vegetation on open plaur, mixed reed vegetation, vegetation in depressions between dunes and mixed Typha detection; radar/optical data integration provides reliable results for dune forests, dune vegetation, reed vegetation on open plaur, mixed reed vegetation, salt-tolerant vegetation and mixed Typha detection; optical/LiDAR data integration exhibits reliable results for all twelve classes; radar/LiDAR data integration also exhibits reliable results for dune forests, dune vegetation and salt-tolerant vegetation detection; finally, optical/radar/LiDAR data integration exhibits reliable results for all classes, except for the pure reed vegetation $(78.8 \%)$ and mixed sedge vegetation (74.6\%) classes (table 5).

TABLE 6

CAPABILITY OF SENSORS TO DISCRIMINATE THE DIFFERENT VEGETATION CLASSES 


\begin{tabular}{|c|c|c|}
\hline Sensor & $\begin{array}{c}\text { Good } \\
\text { discrimination }(>80 \% \\
\text { accuracy) }\end{array}$ & Confusion \\
\hline SPOT & $\begin{array}{c}\text { Dune vegetation, } \\
\text { reed vegetation on open } \\
\text { plaur, mixed reed } \\
\text { vegetation, vegetation in } \\
\text { depressions between } \\
\text { dunes, mixed Typha }\end{array}$ & Dune forest \\
\hline RADARSAT-2 & Dune forest & $\begin{array}{c}\text { Reed vegetation on } \\
\text { compact plaur, reed } \\
\text { vegetation and bushes on } \\
\text { compact plaur }\end{array}$ \\
\hline LiDAR & $\begin{array}{l}\text { Dune forest, dune } \\
\text { vegetation, mixed } \\
\text { Typha }\end{array}$ & $\begin{array}{c}\text { Reed vegetation on } \\
\text { compact plaur, mixed reed } \\
\text { vegetation }\end{array}$ \\
\hline $\begin{array}{c}\text { SPOT/RADARSAT- } \\
2\end{array}$ & $\begin{array}{c}\text { Dune forest, dune } \\
\text { vegetation, reed } \\
\text { vegetation on open } \\
\text { plaur, mixed reed } \\
\text { vegetation, salt-tolerant } \\
\text { vegetation, mixed } \\
\text { Typha }\end{array}$ & Mixed sedge vegetation \\
\hline SPOT/LiDAR & All classes & Very little \\
\hline $\begin{array}{l}\text { RADARSAT- } \\
\text { 2/LiDAR }\end{array}$ & $\begin{array}{c}\text { Dune forest, dune } \\
\text { vegetation, salt-tolerant } \\
\text { vegetation }\end{array}$ & $\begin{array}{l}\text { Reed vegetation on } \\
\text { compact plaur, mixed } \\
\text { sedges vegetation }\end{array}$ \\
\hline $\begin{array}{l}\text { SPOT/RADARSAT- } \\
\text { 2/LiDAR }\end{array}$ & $\begin{array}{l}\text { All classes except } \\
\text { pure reed vegetation and } \\
\text { mixed sedge vegetation }\end{array}$ & $\begin{array}{l}\text { Pure reed vegetation, } \\
\text { mixed sedge vegetation }\end{array}$ \\
\hline
\end{tabular}

This paper deals with the contribution of multi-source remote sensing data for vegetation recognition in the Danube Delta wetlands. The proposed method should be transferable to other large wetlands that are characterized by similar physiological settings and vegetation types.

\section{Acknowledgements}

The authors want to thank Prof. Dar Roberts (UC Santa Barbara, Department Geography, USA) for supporting this research with valuable recommendations and useful suggestions. We thank Paul Gagnon (Sherbrook, Canada) for his attentive comments on the manuscript.

\section{REFERENCES}

[1] J. Töyrä and A. Pietroniro, «Towards operational monitoring of a northern wetland using geomatics-based techniques », Remote Sensing of Environment, vol. 97, ${ }^{\circ}$ 2, p. 174-191, 2005.

[2] S. L. Ozesmi and M. E. Bauer, "Satellite remote sensing of wetlands," Wetlands Ecology and Management, vol. 10, $\mathrm{n}^{\circ}$ 5, pp. 381-402, 2014.

[3] R. Dubayah, R. Knox, M. Hofton, JB. Blair and J. M.Drake, "Land surface characterization using LiDAR remote sensing", in J. Hill and R. J. Aspinall, Spatial Information for Land Use Management. CRC Press, 2000.

[4] J. E. Anderson, Spectral signature of wetland plants (350-900). USA Army Topographic Engineering Centre, Alexandria (VA), 1995.

[5] S. V. Stehman, J. D. Wickham, J. H. Smith, and L. Yang, « Thematic accuracy of the 1992 National Land-Cover Data for the eastern United States: Statistical methodology and regional results », Remote Sensing of Environment, vol. 86, ${ }^{\circ}$ 4, p. 500-516, 2003.

[6] J. D. Wickham, S. V. Stehman, J. H. Smith and L. Yang, «Thematic accuracy of the 1992 National Land-Cover Data for the western United States », Remote Sensing of Environment, vol. 91, $\mathrm{n}^{\circ}$ 3-4, p. 452-468, 2004.
[7] C. Wright and A. Gallant, «Improved wetland remote sensing in Yellowstone National Park using classification trees to combine TM imagery and ancillary environmental data », Remote Sensing of Environment, vol. 107, $\mathrm{n}^{\circ}$ 4, p. 582-605, 2007.

[8] C. Baker, R. Lawrence, C. Montagne and D. Patten, "Mapping wetlands and riparian areas using Landsat ETM+ imagery and decision-tree-based models," Wetlands, vol. 26, n 2, pp. 465-474, 2006.

[9] A. M. B. May, J. E Pinder and G. C Kroh, "A comparison of LANDSAT Thematic Mapper and SPOT multi-spectral imagery for the classification of shrub and meadow vegetation in Northern California", USA, Journal Remote Sensing, 18, 3719-3728, 1997.

[10] K. R. Harvey and G. J. E. Hill, "Vegetation mapping of a tropical freshwater swamp in the Northern Territory, Australia: A comparison of aerial photography, Landsat TM and SPOT satellite imagery," International Journal of Remote Sensing, vol. 22, $\mathrm{n}^{\circ}$ 15, pp. 2911-2925, 2001.

[11] J. Li and W. Chen, "A rule-based method for mapping Canada's wetlands using optical, radar and DEM data," International Journal of Remote Sensing, vol. 26, $\mathrm{n}^{\circ} 22$, pp. 5051-5069, 2005.

[12] E. Belluco, M. Camuffo, S. Ferrari, L. Modenese, S. Silvestri, A. Marani and M. Marani, "Mapping salt-marsh vegetation by multispectral and hyperspectral remote sensing," Remote Sensing of Environment, vol. 105, $\mathrm{n}^{\circ} 1$, pp. 54-67, 2006

[13] K. S. Schmidt and A. K. Skidmore, "Spectral discrimination of vegetation types in a coastal wetland », Remote Sensing of Environment, vol. $85, \mathrm{n}^{\circ} 1$, p. $92-108,2003$.

[14] P. H. Rosso, S. L. Ustin and A. Hastings, « Use of lidar to study changes associated with Spartina invasion in San Francisco Bay marshes », Remote Sensing of Environment, vol. 100, n 3, p. 295-306, 2006.

[15] B. W. Pengra, C. A. Johnston and T. R. Loveland, "Mapping an invasive plant, Phragmites australis, in coastal wetlands using the EO-1 Hyperion hyperspectral sensor," Remote Sensing of Environment, vol. 108, $\mathrm{n}^{\mathrm{o}}$ 1, pp. $74-81,2007$.

[16] C. Vaiphasa, S. Ongsomwang, T. Vaiphasa and A. K. Skidmore, «Tropical mangrove species discrimination using hyperspectral data: A laboratory study », Estuarine, Coastal and Shelf Science, vol. 65, $\mathrm{n}^{\circ}$ 1-2, p. 371-379, 2005.

[17] K. E. Sawaya, L. G. Olmanson, N. J. Heinert, P. L. Brezonik and M. E. Bauer, « Extending satellite remote sensing to local scales: land and water resource monitoring using high-resolution imagery », Remote Sensing of Environment, vol. 88, $\mathrm{n}^{\circ}$ 1-2, p. 144-156, 2003.

[18] L. Wang, W. P. Sousa and P. Gong, «Integration of object-based and pixel-based classification for mapping mangroves with IKONOS imagery », International Journal of Remote Sensing, vol. 25, $\mathrm{n}^{\circ}$ 24, p. 5655-5668, 2004

[19] C. Wang, M. Menenti, M.P. Stoll, A. Feola, E. Belluco and M. Marani, "Separation of ground and low vegetation signatures in LiDAR measurements of salt-marsh environments", IEEE Transactions on Geoscience and Remote Sensing, 47(7), 2014-202, 2009.

[20] J. F. Weishampel, J. B. Blair, R. G. Knox, R. Dubayah and D. B. Clark, «Volumetric lidar return patterns from an old-growth tropical rainforest canopy », International Journal of Remote Sensing, vol. 21, $\mathrm{n}^{\circ} 2$, $\mathrm{p}$. $409-415,2000$

[21] A. Davranche, G. Lefebvre and B. Poulin, "Wetland monitoring using classification trees and SPOT-5 seasonal time series," Remote Sensing of Environment, vol. 114, $\mathrm{n}^{\circ}$ 3, pp. 552-562, 2010.

[22] A. J. Lewis, "Geomorphic and hydrologic applications of active microwave remote sensing". In F. M. Henderson and A.J. Lewis (Eds). Principles and Applications of Imaging Radar: Manual of Remote Sensing, NY, Wiley, 567-629, 1998.

[23] L. L. Hess, J. M. Melack, E. M. L. M. Novo, C. C. F. Barbosa and M. Gastil, "Dual-season mapping of wetland inundation and vegetation for the central Amazon basin," Remote Sensing of Environment, vol. 87, $\mathrm{n}^{\circ} 4$, pp. 404-428, 2003.

[24] M. S. Horritt, D. C. Mason, D. M. Cobby, I. J. Davenport and P. D. Bates, "Waterline mapping in flooded vegetation from airborne SAR imagery," Remote Sensing of Environment, vol. 85, n ${ }^{\circ}$ 3, pp. 271-281, 2003.

[25] B. Brisco, A. Schmitt, K. Murnaghan, S. Kaya and A. Roth, "SAR polarimetric change detection for flooded vegetation," International Journal of Digital Earth, vol. 6, n 2, pp. 103-114, 2013.

[26] M. P. F. Costa, O. Niemann, E. Novo and F. Ahern, "Biophysical properties and mapping of aquatic vegetation during the hydrological cycle of the Amazon floodplain using JERS-1 and Radarsat," 
International Journal of Remote Sensing, vol. 23, $\mathrm{n}^{\circ}$ 7, pp. 1401-1426, 2002.

[27] L. L. Bourgeau-Chavez, K. P. Kowalski, M. L. Carlson Mazur, K. A. Scarbrough, R. B. Powell, C. N. Brooks, B. Huberty, L. K. Jenkins, E. C. Banda, D. M. Galbraith, Z. M. Laubach and K. Riordan, "Mapping invasive Phragmites australis in the coastal Great Lakes with ALOS PALSAR satellite imagery for decision support," Journal of Great Lakes Research, vol. 39, Supplement 1, pp. 65-77, 2013.

[28] R. Touzi, A. Deschamps and G. Rother, « Wetland characterization using polarimetric RADARSAT-2 capability », Canadian Journal of Remote Sensing, vol. 33, $\mathrm{n}^{\circ}$ sup1, p. S56-S67, 2007.

[29] R. Touzi, A. Deschamps and G. Rother, «Phase of Target Scattering for Wetland Characterization Using Polarimetric C-Band SAR », IEEE Transactions on Geoscience and Remote Sensing, vol. 47, $\mathrm{n}^{\circ}$ 9, $\mathrm{p}$. 3241-3261, 2009.

[30] M. Koch, T. Schmid, M. Reyes and J. Gumuzzio, "Evaluating Full Polarimetric C- and L-Band Data for Mapping Wetland Conditions in a Semi-Arid Environment in Central Spain”, IEEE Journal International Geoscience and Remote Sensing (IGARSS), 1033-1044, 2012.

[31] T. L. Evans and M. Costa, "Landcover classification of the Lower Nhecolândia subregion of the Brazilian Pantanal Wetlands using ALOS/PALSAR, RADARSAT-2 and ENVISAT/ASAR imagery," Remote Sensing of Environment, vol. 128, pp. 118-137, 2013.

[32] J. Töyrä, A. Pietroniro and L. W. Martz, «Multi-sensor Hydrologic Assessment of a Freshwater Wetland », Remote Sensing of Environment, vol. $75, \mathrm{n}^{\circ} 2$, p. 162-173, 2001.

[33] P. A. Townsend, « Mapping seasonal flooding in forested wetlands using multi-temporal Radarsat SAR », Photogrammetric Engineering and Remote Sensing, vol. 67, $\mathrm{n}^{\circ}$ 7, p. 857-864, 2001.

[34] F. M. Grings, P. Ferrazzoli, J. C. Jacobo-Berlles, H. Karszenbaum, J. Tiffenberg, P. Pratolongo and P. Kandus, "Monitoring flood condition in marshes using EM models and Envisat ASAR observations," IEEE Transactions on Geoscience and Remote Sensing, vol. 44, n 4, pp. 936942, 2006.

[35] E. S. Kasischke and L. L. Bourgeau-Chavez, "Monitoring South Florida wetlands using ERS-1 SAR imagery," Photogrammetric Engineering and Remote Sensing, vol. 63, n 3, pp. 281-291, 1997.

[36] F. M. Henderson and A. J. Lewis, "Radar detection of wetland ecosystems: a review," International Journal of Remote Sensing, vol. 29, n 20 , pp. 5809-5835, 2008.

[37] E. Ramsey, III, "Radar remote sensing of wetlands", Remote Sensing Change Detection: Environmental Monitoring Methods and Applications, R. Lunetta and C. Elvidge (Eds). Chapter 13, 211-243, 1998.

[38] D. K. Hall, "Remote sensing applications to hydrology; imaging radar," Hydrological Sciences Journal, vol. 41, nº 4, pp. 609-624, 1996.

[39] E. S. Kasischke, J. M. Melack and M. Craig Dobson, "The use of imaging radars for ecological applications-A review," Remote Sensing of Environment, vol. 59, $\mathrm{n}^{\circ}$ 2, pp. 141-156, 1997.

[40] S. R. Phinn, D. A. Stow and D. Van Mouwerik, "Remotely sensed estimates of vegetation structural characteristics in restored wetlands, Southern California," Photogrammetric Engineering and Remote Sensing, vol. 65, no 4, pp. 485-493, 1999.

[41] B. R. M. Rao, R. S. Dwivedi, S. P. S. Kushwaha, S. N. Bhattacharya, J. B. Anand and S. Dasgupta, "Monitoring the spatial extent of coastal wetlands using ERS-1 SAR data," International Journal of Remote Sensing, vol. 20, n 13, pp. 2509-2517, 1999.

[42] B. A. Wilson and H. Rashid, « Monitoring the 1997 flood in the Red River Valley using hydrologic regimes and RADARSAT imagery », Canadian Geographer / Le Géographe canadien, vol. 49, $\mathrm{n}^{\circ}$ 1, p. 100-109, 2005.

[43] V. Klemas, "Remote sensing of emergent and submerged wetlands: an overview," International Journal of Remote Sensing, vol. 34, $\mathrm{n}^{\circ} 18$, pp. 6286-6320, 2013.

[44] S. H. Hong, S. Wdowinski and S. W. Kim, "Evaluation of TerraSAR-X Observations for Wetland InSAR Application". IEEE Transactions on Geoscience and Remote Sensing, 48, 864-873, 2010.

[45] Y.-K. Lee, J.-W. Park, J.-K. Choi, Y. Oh and J.-S. Won, « Potential uses of TerraSAR-X for mapping herbaceous halophytes over salt marsh and tidal flats », Estuarine, Coastal and Shelf Science, vol. 115, p. 366-376, 2012

[46] K. Zalite, K. Voormansik, A. Olesk, M. Noorma and A. Reinart, « Effects of Inundated Vegetation on X-Band HH-VV Backscatter and Phase Difference », IEEE Journal of Selected Topics In Applied Earth Observations And Remote Sensing, vol. 7, n ${ }^{\circ}$ 4, p. 1402-1406, 2014.
[47] Sang-Hoon Hong, Hyun-Ok Kim, Shimon Wdowinski and E. Feliciano, «Evaluation of Polarimetric SAR Decomposition for Classifying Wetland Vegetation Types », Remote Sensing, vol. 7, n ${ }^{\circ}$ 7, p. 8563-8585, 2015.

[48] Schuster, C., Schmidt, T., Conrad, C., Kleinschmit, B., Förster, M., Grassland habitat mapping by intra-annual time series analysis comparison of RapidEye and TerraSAR-X satellite data. Int. J. Appl. Earth Obs. Geoinf. 34, 25-34, 2015.

[49] Betbeder, J., Rapinel, S., Corpetti, T., Pottier, E., Corgne, S. and HubertMoy, L., Multitemporal classification of TerraSAR-X data for wetland vegetation mapping. J. Appl. Remote Sens. 8 (1), 2014.

[50] R. D. Ward, N. G. Burnside, C. B. Joyce and K. Sepp, « The use of medium point density LiDAR elevation data to determine plant community types in Baltic coastal wetlands », Ecological Indicators, vol. 33, p. 96-104, 2013.

[51] C. Huang, Y. Peng, M. Lang, I.-Y. Yeo and G. McCarty, «Wetland inundation mapping and change monitoring using Landsat and airborne LiDAR data », Remote Sensing of Environment, vol. 141, p. 231-242, 2014

[52] S. Luo, C. Wang, F. Pan, X. Xi, G. Li, S. Nie and S. Xia, « Estimation of wetland vegetation height and leaf area index using airborne laser scanning data », Ecological Indicators, vol. 48, p. 550-559, 2015.

[53] J. Corcoran, J. Knight, K. Pelletier, L. Rampi and Yan Wang, "The Effects of Point or Polygon Based Training Data on Random Forest Classification Accuracy of Wetlands », Remote Sensing, vol. 7, $\mathrm{n}^{\circ}$ 4, p. 4002-4025, 2015.

[54] J. Populus, G. Barreau, J. Fazilleau, M. Kerdreux and J. LTfavanc, "Assessment of the LiDAR topographic technique over a coastal area". Proceedings of CoastGIS'Ol: $4 t^{h}$ International Symposium on GIS and Computer Mapping for Coastal Zone Management (CoastGIS, Halifax, Nova Scotia), 11 p, 2001.

[55] J. Gopfert and C. Heipke, "Assessment of LiDAR DTM in coastal vegetated areas", International Archives of Photogrammetry, Remote Sensing, and Spatial Information Sciences, 36(3), 79-85, 2006.

[56] K. A. Schmid, B. C. Hadley and N. Wijekoon, « Vertical Accuracy and Use of Topographic LiDAR Data in Coastal Marshes », Journal of Coastal Research, p. 116-132, 2011.

[57] C. Hopkinson, L. E. Chasmer, G. Sass, I. F. Creed, M. Sitar, W. Kalbfleisch and P. Treitz, "Vegetation class dependent errors in lidar ground elevation and canopy height estimates in a boreal wetland environment," Canadian Journal of Remote Sensing, vol. 31, $\mathrm{n}^{\circ}$ 2, pp. 191-206, 2005.

[58] G. Chust, I. Galparsoro, Á. Borja, J. Franco and A. Uriarte, "Coastal and estuarine habitat mapping, using LiDAR height and intensity and multispectral imagery," Estuarine, Coastal and Shelf Science, vol. 78, n ${ }^{\circ}$ 4, pp. 633-643, 2008.

[59] C. Hladik and M. Alber, "Accuracy assessment and correction of a LiDAR-derived salt marsh digital elevation model," Remote Sensing of Environment, vol. 121, pp. 224-235, 2012.

[60] C. Hopkinson,L.E.Chasmer, G.Zsigovics,I.F.Creed,M.Sitar,P. Treitz, and R.V. Maber, "Errors in LIDAR ground elevations and wetland vegetation height estimates", International Archives of Photogrammetry, Remote Sensing, and Spatial Information Sciences, 36(8), 108-113, 2004.

[61] M. A. Lefsky, W. B. Cohen, G. G. Parker and D. J. Harding, "LiDAR Remote Sensing for Ecosystem Studies LiDAR, an emerging remote sensing technology that directly measures the three-dimensional distribution of plant canopies, can accurately estimate vegetation structural attributes and should be of particular interest to forest, landscape, and global ecologists," BioScience, vol. 52, no. 1, pp. 19-30, 2002

[62] K. T. Vierling, L. A. Vierling, W. A. Gould, S. Martinuzzi and R. M. Clawges, "LiDAR: shedding new light on habitat characterization and modeling », Frontiers in Ecology and the Environment, vol. 6, $\mathrm{n}^{\circ}$ 2, p. 90-98, 2008.

[63] P. H. Rosso, S. L. Ustin and A. Hastings, «Use of LiDAR to study changes associated with Spartina invasion in San Francisco Bay marshes », Remote Sensing of Environment, vol. 100, $\mathrm{n}^{\circ} 3$, p. 295-306, 2006.

[64] K. Clint Slatton, M. M. Crawford and L.-D. Chang, « Modeling temporal variations in multipolarized radar scattering from intertidal coastal wetlands », ISPRS Journal of Photogrammetry and Remote Sensing, vol. $63, \mathrm{n}^{\circ} 5$, p. 559-577, 2008. 
[65] T. R. Allen, Y. Wang and B. Gore, "Coastal wetland mapping combining multi-date SAR and LiDAR," Geocarto International, vol. 28, $\mathrm{n}^{\circ}$ 7, pp. 616-631, 2013.

[66] M. Maxa and P. Bolstad, "Mapping northern wetlands with high resolution satellite images and LiDAR," Wetlands, vol. 29, $\mathrm{n}^{\circ} 1$, pp. 248$260,2009$.

[67] A. O. Onojeghuo and G. A. Blackburn, "Optimising the use of hyperspectral and LiDAR data for mapping reedbed habitats," Remote Sensing of Environment, vol. 115, $\mathrm{n}^{\circ}$ 8, pp. 2025-2034, 2011.

[68] K. B. Moffett and S. M. Gorelick, "Distinguishing wetland vegetation and channel features with object-based image segmentation," International Journal of Remote Sensing, vol. 34, nº 4, pp. 1332-1354, 2013.

[69] K. C. Slatton, M. M. Crawford and B. L. Evans, « Fusing interferometric radar and laser altimeter data to estimate surface topography and vegetation heights », IEEE Transactions on Geoscience and Remote Sensing, vol. 39, $\mathrm{n}^{\circ} 11$, p. 2470-2482, 2001.

[70] P. Hyde, R. Dubayah, W. Walker, J. B. Blair, M. Hofton and C. Hunsaker, "Mapping forest structure for wildlife habitat analysis using multi-sensor (LiDAR, SAR/InSAR, ETM+, Quickbird) synergy," Remote Sensing of Environment, vol. 102, $\mathrm{n}^{\circ} 1-2$, pp. 63-73, 2006.

[71] J. Hanganu, D. Dubyna, E. Zhmud, I. Grigoras, U. Menke, H. Drost, N. Ştefan and I. Sărbu, "Vegetation of the Biosphere Reserve "Danube Delta" - with Transboundary Vegetation Map on a 1:150,000 scale", RIZA rapport, Lelystad, 2002.

[72] V. Ciocârlan, «Flora Deltei Dunarii ». Cormophyta, Bucuresti, Editura Ceres, 1994.

[73] Spot Image, "Preprocessing levels and location accuracy", Technical information, www.spotimage.com., 2014.

[74] O. De Joinville, B. Ferrand et M. Roux, "Levé laser aéroporté: État de l'art, traitement des données, évaluation et comparaison avec des corrélations d'images," in Bulletin - Société française de photogrammétrie et de télédétection, 2002, pp. 72-81.

[75] B. Bergeon, «L'altimétrie par laser scanner aéroporté », Géomatique Expert, 35, 19-24, 2004.

[76] D. J. Harding, M. A. Lefsky, G. G. Parker and J. B. Blair, "Laser altimeter canopy height profiles: methods and validation for closed-canopy, broadleaf forests," Remote Sensing of Environment, vol. 76, n 3, pp. 283297, 2001.

[77] P. Axelsson, "Processing of laser scanner data-algorithms and applications," ISPRS Journal of Photogrammetry and Remote Sensing, vol. 54, nº 2-3, pp. 138-147, 1999.

[78] E. P. Baltsavias, "Airborne laser scanning: existing systems and firms and other resources," ISPRS Journal of Photogrammetry and Remote Sensing, vol. 54, nº 2-3, pp. 164-198, 1999.

[79] C. Lardeux, P.-L. Frison, C. Tison, J.-C. Souyris, B. Stoll, B. Fruneau and J.-P. Rudant, "Support Vector Machine for Multifrequency SAR Polarimetric Data Classification," IEEE Transactions on Geoscience and Remote Sensing, vol. 47, $\mathrm{n}^{\circ} 12$, pp. 4143-4152, 2009.

[80] R. G. Congalton and K. Green, Assessing the Accuracy of Remotely Sensed Data: Principles and Practices, Second Edition. CRC Press, 2008.

[81] R. G. Congalton, "A review of assessing the accuracy of classifications of remotely sensed data," Remote Sensing of Environment, vol. 37, n ${ }^{\circ} 1$, pp. $35-46,1991$.

[82] D. R. Streutker and N. F. Glenn, «LiDAR measurement of sagebrush steppe vegetation heights », Remote Sensing of Environment, vol. 102, $\mathrm{n}^{\circ}$ $1-2$, p. $135-145,2006$

[83] G. Guyot, "Optical properties of vegetation canopies", In: Steven MD, Clark JA (eds), Application of Remote Sensing in Agriculture, Butterworths, London, pp 19-44, 1990.

[84] T. J. Malthus and D. G. George, "Airborne remote sensing of macrophytes in Cefni reservoir", Aquat Botanic, Anglesley, UK., 58, 317-332, 1997.

[85] L. Yuan and L. Zhang, «Identification of the spectral characteristics of submerged plant Vallisneria spiralis », Acta Ecologica Sinica, vol. 26, $\mathrm{n}^{\circ}$ 4, p. 1005-1010, 2006.

[86] E. L. Hestir, S. Khanna, M. E. Andrew, M. J. Santos, J. H. Viers, J. A. Greenberg, S. S. Rajapakse and S. L. Ustin, "Identification of invasive vegetation using hyperspectral remote sensing in the California Delta ecosystem," Remote Sensing of Environment, vol. 112, n 11, pp. 40344047, 2008

[87] R. J. Zomer, A. Trabucco and S. L. Ustin, « Building spectral libraries for wetlands land cover classification and hyperspectral remote sensing », Journal of Environmental Management, vol. 90, n 7, p. 2170-2177, 2009.
[88] K. R. Harvey and G. J. E. Hill, "Vegetation mapping of a tropical freshwater swamp in the Northern Territory, Australia: A comparison of aerial photography, Landsat TM and SPOT satellite imagery," International Journal of Remote Sensing, vol. 22, $\mathrm{n}^{\circ}$ 15, pp. 2911-2925, 2001.

[89] J. McCarthy, T. Gumbricht and T. S. McCarthy, "Ecoregion classification in the Okavango Delta, Botswana from multi-temporal remote sensing," International Journal of Remote Sensing, vol. 26, $\mathrm{n}^{\circ}$ 19, pp. 4339-4357, 2005.

[90] L. L. Hess, J. M. Melack and D. S. Simonett, "Radar detection of flooding beneath the forest canopy: a review," International Journal of Remote Sensing, vol. 11, $\mathrm{n}^{\circ}$ 7, pp. 1313-1325, 1990.

[91] S. Paloscia, "A summary of experimental results to assess the contribution of SAR for mapping vegetation biomass and soil moisture," Canadian Journal of Remote Sensing, vol. 28, n 2, pp. 246-261, 2002.

[92] J. Shi, J. Wang, A. Y. Hsu, P. E. O’Neill and E. T. Engman, «Estimation of bare surface soil moisture and surface roughness parameter using Lband SAR image data », IEEE Transactions on Geoscience and Remote Sensing, vol. 35, $\mathrm{n}^{\circ} 5$, p. 1254-1266, 1997.

[93] M. Moghaddam, J. L. Dungan and S. Acker, « Forest variable estimation from fusion of SAR and multispectral optical data », IEEE Transactions on Geoscience and Remote Sensing, vol. 40, n ${ }^{\circ}$ 10, p. 2176-2187, 2002.

[94] F. M. Henderson, R. Chasan, J. Portolese and T. Hart Jr, "Evaluation of SAR-optical imagery synthesis techniques in a complex coastal ecosystem," Photogrammetric Engineering and Remote Sensing, vol. 68, $n^{\circ}$ 8, pp. 839-846, 2002.

[95] X. Yang, "Integrated use of remote sensing and geographic information systems in riparian vegetation delineation and mapping", Journal Remote Sensing, 28, 353-370, 2007.

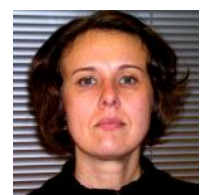

Dr. Simona Niculescu received the Ph.D. degree in Geography from the Université de Paris IV-Sorbonne (France) in 2002. Since 2005 she is with the LETG-Géomer UMR 6554 CNRS lab within the European Institute for Marine Studies in Brest. The researcher's current research topic deals with coastal areas, and hence deltas. She focuses on methodologies for exploiting the opportunities offered by the new satellite images.

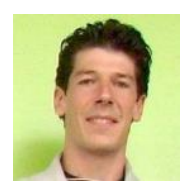

Dr. Cédric Lardeux was born in 1980. He received the M.S. and Ph.D. degrees in science of geographic information from the Université Paris-Est Marne-la-Vallée, Marne-la-Vallée, France, in 2005 and 2008, respectively. He occupied a Postdoctoral position with the SAPHIR Team, Université de Rennes, Rennes, France, where he is involved in radar polarimetry for the mapping of tropical vegetation. At Present, he works at ONF International as a remote sensing and GIS expert.

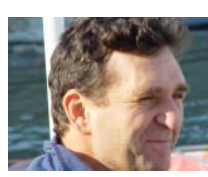

Dr. Grigoras Ion, 58 year old, has a degree in Electronics and Telecommunication Engineering. In 1995-1996 he graduated in a GIS and remote sensing course at University of Massachusetts. He holds a PhD Degree in Geography (2003). He has extensive experience (20 years) using GIS for nature conservation purposes, knowledge in GIS, mapping, programming, analyses, remote sensing and databases for biodiversity and environmental protection.

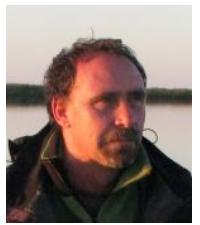

Dr. Jenică Hanganu was born in 1956. He is a senior scientist. Since 1984, he is employed by the Danube Delta National Institute for Research and Development, in Romania. His main activities are focussed on vegetation and soil surveys and mapping, remote sensing and photointerpretation.

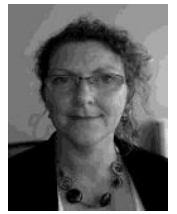

Laurence DAVID was born in Rennes, France, in 1971. She received the DESS degree in Geography from the Universite de Rennes in 1997. From 1998 to 2007, she had her own business in cartography. Since 2008, she is cartographer at the LETG laboratory (UMR 6554 CNRS) in Brest. 